Article

\title{
Antifungal and Antivirulence Activities of Hydroalcoholic Extract and Fractions of Platonia insignis Leaves against Vaginal Isolates of Candida Species
}

\author{
Anderson França da Silva ${ }^{1}$, Cláudia Quintino da Rocha ${ }^{2}$, Luís Cláudio Nascimento da Silva ${ }^{3}$, \\ Alexsander Rodrigues Carvalho Júnior ${ }^{3}$, Iven Neylla Farias Vale Mendes ${ }^{4}$, \\ Andrea Borges de Araruna ${ }^{1}$, Elizangela Pestana Motta ${ }^{1}$, Rayssa de Sousa Silva ${ }^{5}$, \\ Carmem Duarte Lima Campos ${ }^{5}$, Josivan Regis Farias ${ }^{1}$, Aluísio da Silva Oliveira ${ }^{1}$, \\ Douglas Henrique dos Santos Silva ${ }^{6}$, Flávia Raquel F Nascimento ${ }^{1}$, \\ Rosane Nassar Meireles Guerra ${ }^{1, *}$ and Cristina Andrade Monteiro ${ }^{5,7, * \text { (D }}$ \\ 1 Laboratório de Imunofisiologia, Programa de Doutorado em Biotecnologia-RENORBIO, \\ Universidade Federal do Maranhão, 65085-580 São Luís, Ma, Brazil; \\ andersonsilva.ppgcs@ufma.br (A.F.d.S.); andreaborges19@hotmail.com (A.B.d.A.); \\ elifarmabr@gmail.com (E.P.M.); regis.farias95@gmail.com (J.R.F.); as.olivira@ufma.br (A.d.S.O.); \\ flavia.nascimento@ufma.br (F.R.F.N.) \\ 2 Laboratório de Química de Produtos Naturais, Centro de Ciências Exatas e Tecnológicas, \\ Universidade Federal do Maranhão, 65085-580 São Luís, Ma, Brazil; rocha.claudia@ufma.com.br \\ 3 Laboratório de Imunologia das Doenças Infecciosas e Parasitárias, Programa de Mestrado em Biologia \\ Microbiana, Universidade Ceuma, 65075-120 São Luís, Ma, Brazil; luis.claudio@ceuma.br (L.C.N.d.S.); \\ aecarvalhojr@usp.br (A.R.C.J.) \\ 4 Departamento de Ensino, Instituto Federal do Maranhão, 65485-000 Itapecuru-Mirim, Ma, Brazil; \\ iven.mendes@ifma.edu.br \\ 5 Laboratório de Microbiologia Aplicada, Programa de Biologia Microbiana, Universidade Ceuma, \\ 65075-120 São Luís, Ma, Brazil; ra.silva2706@gmail.com (R.d.S.S.); carmemdlcampos@gmail.com (C.D.L.C.) \\ 6 Laboratório de Microbiologia Aplicada, Curso de Especialização em Microbiologia Clínica, \\ Universidade Ceuma, 65075-120 São Luís, Ma, Brazil; douglasbmdh@gmail.com \\ 7 Departamento de Biologia, Instituto Federal do Maranhão, 65030-005 São Luís, Ma, Brazil \\ * Correspondence: rosane.guerra@ufma.br (R.N.M.G.); cristina.monteiro@ceuma.br (C.A.M.); \\ Tel.: +55-98982947406 (C.A.M.)
}

Received: 23 December 2019; Accepted: 16 January 2020; Published: 28 January 2020

\begin{abstract}
Vulvovaginal candidiasis is a common fungal infection in women. In this study, Platonia insignis hydroalcoholic extract (PiHE) and its fractions were evaluated for antifungal and antivirulence activities against vaginal Candida species. Dichloromethane (DCMF) and ethyl acetate fractions (EAF) obtained from PiHE effectively inhibited the pathogen. Electrospray ionization mass spectrometry was used for identifying the main compounds in extracts. Minimal inhibitory and fungicidal concentrations (MIC and MFC, respectively) were determined by a broth microdilution assay. Furthermore, we evaluated the effect of the extract and fractions on the virulence properties of Candida albicans, and their cytotoxicity effect was determined on RAW 264.7 cells. Compounds found in extracts were flavonoid glycosides, mainly derivatives of quercetin and myricetin. Extracts showed antifungal potential, with the lowest MIC value for EAF $(1.3 \mathrm{mg} / \mathrm{mL})$ and inhibited Candida adherence and biofilm formation. EAF disrupted $48 \mathrm{~h}$ biofilms with an inhibition rate of more than $90 \%$. The extract and its fractions exhibited no cytotoxicity. The antifungal effects were attributed to the ability of these extracts to alter the mitochondrial membrane potential for the release of pro-apoptotic factors in the cytosol. In conclusion, our data suggest that PiHE and EAF could act as novel candidates for the development of new therapeutic treatments against fungal infections.
\end{abstract}


Keywords: Candida albicans; Candida glabrata; vulvovaginal candidiasis; Platonia insignis; biofilm; antifungals

\section{Introduction}

Candida albicans is considered the main etiologic agent of vulvovaginal candidiasis (VVC) and is responsible for $80 \%-85 \%$ of cases, followed by Candida glabrata, accounting for $10 \%-20 \%$ of cases [1]. VVC is the most prevalent acute human fungal infection, affecting $50 \%-75 \%$ of women of a childbearing age once in their lifetime, with a $5 \%-8 \%$ chance of developing the severe chronic form, known as recurrent vulvovaginal candidiasis (RVVC) [2]. A recent study estimated that annually, at least 138 million women worldwide are affected by RVVC $[3,4]$.

Risk factors for VVC include pregnancy, oral contraceptives, diabetes mellitus, treatment with broad-spectrum antibiotics, steroids, and immunosuppressive therapies [5]. Virulence factors expressed by Candida spp. are also important for the development of infection, such as the ability to form biofilms [6]. About 80\% of microorganisms live in biofilms [7] and sessile cells within Candida biofilms are resistant to antifungal agents [8].

Currently, the most commonly used antifungal agents for treating VVC are azoles. The treatment of fungal infections has become challenging because of the rapid development of antifungal resistance due to the over-prescription of medications and prophylactic treatments. Adverse effects presented by antifungals, such as cytotoxicity, gastrointestinal disorders, and hepatotoxicity, contribute to the phenomenon [8,9]. Therefore, it is necessary to develop new antifungal agents against Candida spp. to improve the clinical management of fungal diseases.

In Brazil, secondary plant metabolites have been traditionally used for treating fungal diseases due to their antifungal activity. Extracts obtained from plant species native to Brazil that have antifungal activity and exhibit a low cytotoxicity may act as alternatives to the conventional drugs used for the treatment of VVC $[8,10]$.

Platonia insignis belongs to the Clusiaceae family and is popularly known as "bacurizeiro". Native to the Brazilian Amazon forests, P. insignis is a fruit-bearing and woody plant with a dense and diverse distribution throughout the country [11]. Traditionally, it has been used to treat various ailments related to the digestive tract and rapid wound healing, and was also reported to have diuretic and antitumor properties [12,13].

Previous natural product studies have focused on the characterization of fats extracted from seeds used in folk medicine to treat diarrhea, skin problems, earaches, rheumatism, arthritis, and scarring [12-14]. There have been some reports investigating the effects of P. insignis seed compounds as antioxidants, anti-inflammatory agents, cytotoxic agents, and leishmanicidal agents. These were also investigated for their use in treating Alzheimer's and Parkinson's diseases. However, P. insignis leaf extracts have not been well-characterized in terms of their use in treating Candida infections. In this study, we analyzed the phytochemical composition and investigated the in vitro antifungal and antivirulence potential of a hydroethanolic extract of leaves of P. insignis (PiHE), and the dichloromethane (DCMF) and ethyl acetate fractions (EAF) against Candida spp. isolated from vaginal secretions. Furthermore, we verified the cytotoxicity and the effect of these extracts on fungal cells. We hope that leaf extracts of P. insignis can be used in developing effective therapeutic agents against Candida infections.

\section{Results}

\subsection{Phytochemical Characterization}

The qualitative profiles of PiHE were analyzed by FIA-ESI-IT-MS/MS ${ }^{\mathrm{n}}$ and HPLC-PAD-ESI-MS techniques and this resulted in the unambiguous identification of 13 compounds. The full scan spectrum of the ions obtained is shown in Figure 1, and the fragmentation data recorded are listed in 
Table 1. The main secondary metabolites identified were flavonoid glycosides, the main derivatives of quercetin and myricetin. The HPLC-PAD analysis also revealed the presence of peaks corresponding to the typical UV spectra of phenolic acid derivatives. In addition, a fukugentin derivative and flavanone glucosides were detected. The FIA-ESI-IT-MS technique is a powerful tool for the direct and rapid identification of constituents as it does not need any special sample processing. Therefore, it could be used as a starting method for the identification and authentication of $P$. insignis extracts for quality control and assurance.

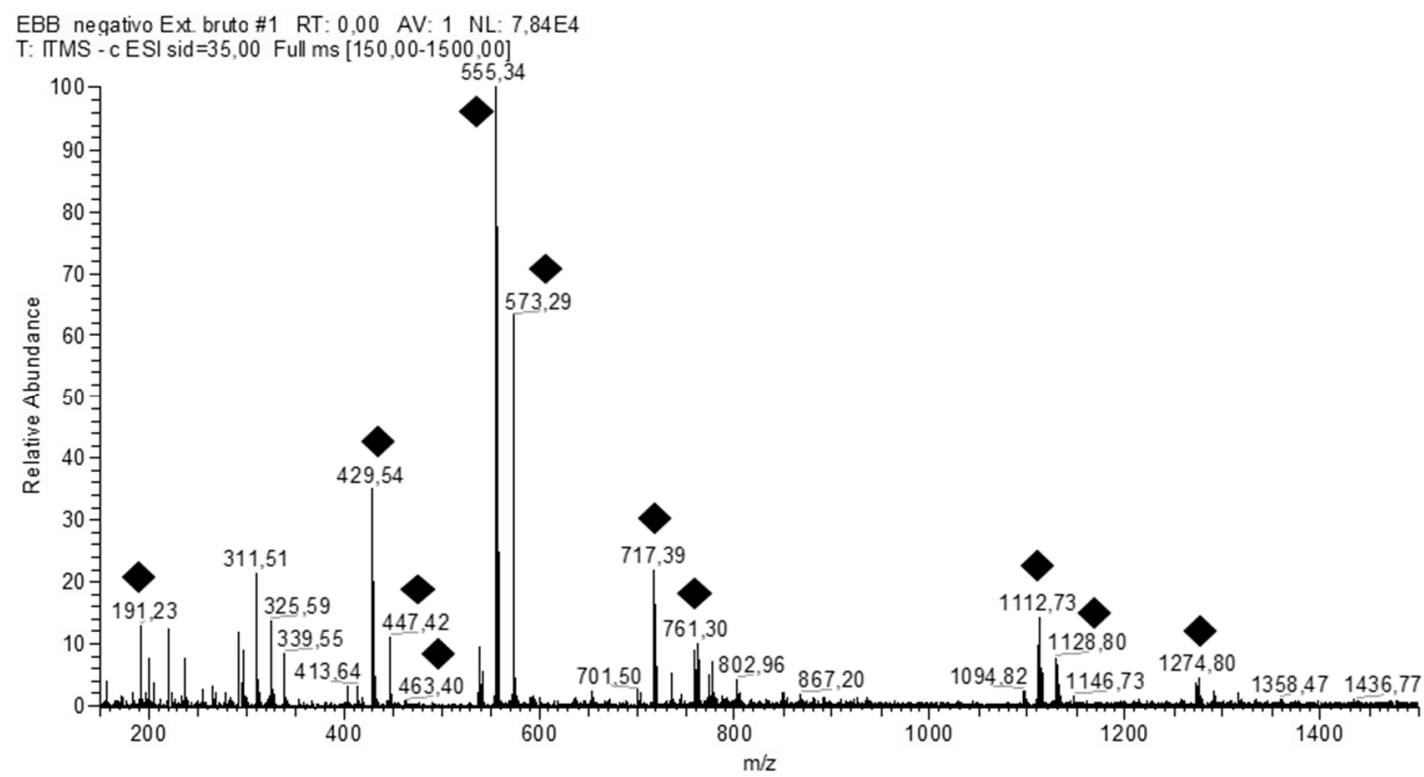

Figure 1. Representative direct flow injection analysis FIA-ESI-IT-MS fingerprint spectra obtained in negative ion mode of the $70 \% \mathrm{EtOH}$ extract from the leaves of Platonia insignis. ( $)$ represents various fragmented constituents.

Table 1. Characterization of the compounds by direct injection in the mass spectrometer.

\begin{tabular}{cccccc}
\hline Sample & Number & {$[\mathbf{M}-\mathbf{H}]^{-}$} & RT & MS $^{\mathbf{n}}$ Fragments & $\begin{array}{c}\text { Names of the } \\
\text { Suggested Structures }\end{array}$ \\
\hline & 1 & 191 & 18.80 & $173,111,85$ & Quinic acid \\
Ononin \\
& 2 & 429 & 18.61 & 267 & Vitexin \\
& 3 & 431 & 18.43 & 295,269 & Orientin \\
& 4 & 447 & 18.24 & $429,419,285,151$ & Fukugentin \\
PiHE & 5 & 555 & 17.42 & $429,401,295,267$ & NI \\
& 6 & 573 & 16.33 & $447,420,419,403,296,269,268$ & Fukugiside \\
& 7 & 717 & 14.31 & $591,565,555,429,403,401,295,267$ & NI \\
& 8 & 761 & 12.49 & $634,608,431$ & NI \\
& 9 & 777 & 10.35 & 447 & Fukugentin dimer \\
& 10 & 1111 & 9.53 & $571,537,509,429$ & Fukugentin dimer \\
& 11 & 1113 & 8.04 & 555,429 & Fukugentin dimer \\
& 12 & 1129 & 6.14 & $1111,1003,877,555,429$ & NI \\
\hline \multirow{6}{*}{ DCMF } & 13 & 1131 & 5.40 & 555,429 & NI \\
& 14 & 1275 & 1.39 & 718,429 & NI \\
& 15 & 573 & 8.34 & $557,431,295,269$ & Ononin \\
& 16 & 555 & 9.12 & $431,429,295,269$ & NI \\
\hline \multirow{5}{*}{ EAF } & 17 & 429 & 9.56 & $429,403,295$ & NI \\
& 18 & 561 & 10.10 & $539,429,413,387$ & Fukugiside \\
& 19 & 573 & 6.40 & $447,419,269$ & Ononin \\
& 20 & 717 & 6.62 & $657,635,55,429$ & Fukugentin \\
& 21 & 429 & 6.69 & 295,269 & NI \\
\hline
\end{tabular}

Legend: PiHE, Platonia insignis hydroalcoholic extract; DCMF, dichloromethane fraction; EAF, ethyl acetate fraction; NI, not identified. 
The chemical structures of the identified flavonoid glycosides are illustrated in Figure 2.<smiles>O=C(O)C1CC(O)C(O)C(O)C1O</smiles>

A) Quinic acid<smiles>COc1ccc(-c2coc3cc(OC4OC(CO)C(O)C(O)C4O)ccc3c2=O)cc1</smiles>

B) Ononin<smiles>O=c1cc(-c2ccc(O)cc2)oc2c(C3OC(CO)C(O)C(O)C3O)c(O)cc(O)c12</smiles>

C) Vitexin<smiles>O=c1cc(-c2ccc(O)c(O)c2)oc2c(C3O[C@H](CO)[C@@H](O)[C@H](O)C3O)c(O)cc(O)c12</smiles>

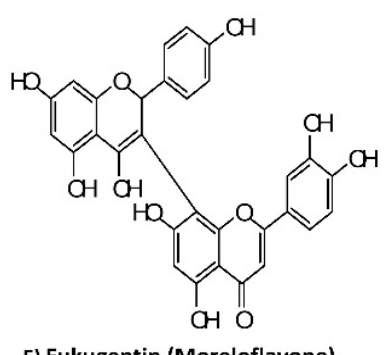

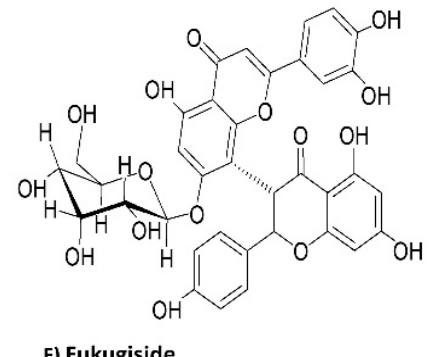

Figure 2. The chemical structures of the identified flavonoid glycosides detected in the crude ethanolic extract and fractions of Platonia insignis.

\subsection{Antifungal Assays}

2.2.1. Determination of the Minimum Inhibitory Concentration (MIC) and Minimum Fungicidal Concentration (MFC)

The antifungal activity of PiHE and its fractions against Candida strains is listed in Tables 2 and 3. For C. albicans isolates, PiHE MIC values ranged from 1.8 to $6.3 \mathrm{mg} / \mathrm{mL}$, MFC from 3.6 to $14.6 \mathrm{mg} / \mathrm{mL}$, and CFM/MIC from 1.3 to $3.6 \mathrm{mg} / \mathrm{mL}$ (Table 2). Comparatively, for C. glabrata isolates, PiHE MICs ranged from 1.6 to $8.3 \mathrm{mg} / \mathrm{mL}$, MFCs from 3.1 to $16.7 \mathrm{mg} / \mathrm{mL}$, and MFC/MIC from 1.0 to $3.3 \mathrm{mg} / \mathrm{mL}$. DCMF showed MICs ranging from 0.7 to 3.1 and 1.0 to $20.8 \mathrm{mg} / \mathrm{mL}$ for C. albicans and C. glabrata, respectively, and MFCs from 2.6 to 10.4 and 1.8 to $20.8 \mathrm{mg} / \mathrm{mL}$ for C. albicans and C. glabrata, respectively (Table 2). The CFM/MIC ratio ranged from 2.9 to 6.4 for C. albicans and 3.6 to 41.7 for C. glabrata. EAF presented the best results in terms of the MIC values, ranging from 0.5 to 1.3 and 0.2 to $1.0 \mathrm{mg} / \mathrm{mL}$ for C. albicans and C. glabrata, respectively; CFM was between 0.5 and 2.6 and 0.3 and $1.6 \mathrm{mg} / \mathrm{mL}$ and the CFM/MIC ratio ranged between 0.8 and 2.0 and 1.5 and 2.5 for C. albicans and C. glabrata, respectively (Table 2).

Table 3 shows the geometric means of the MIC and MFC values of tested substances and the variation of these values for each isolate analyzed. 
Table 2. Antifungal activities of the hydroethanolic extract of Platonia insignis and fractions against vaginal isolates of the Candida spp. and reference strains. All the values are presented in $\mathrm{mg} / \mathrm{mL}$.

\begin{tabular}{|c|c|c|c|c|c|c|c|c|c|c|c|}
\hline \multirow{3}{*}{$\begin{array}{c}\text { STRAINS } \\
\text { Candida albicans }\end{array}$} & \multicolumn{9}{|c|}{ Platonia insignis } & \multicolumn{2}{|c|}{ Antifungals } \\
\hline & \multicolumn{3}{|c|}{ PiHE } & \multicolumn{3}{|c|}{ DCMF } & \multicolumn{3}{|c|}{ EAF } & \multirow{2}{*}{$\begin{array}{c}\text { AMB } \\
\text { MIC }\end{array}$} & \multirow{2}{*}{$\begin{array}{l}\text { FLZ } \\
\text { MIC }\end{array}$} \\
\hline & MIC & MFC & MFC/MIC & MIC & MFC & MFC/MIC & MIC & MFC & MFC/MIC & & \\
\hline $\mathrm{A} 2 \mathrm{Ca}$ & 2.60 & 5.20 & 2.00 & 1.00 & 3.60 & 3.50 & 1.00 & 1.00 & 1.00 & 0.0005 & 0.008 \\
\hline $\mathrm{A} 3 \mathrm{Ca}$ & 1.80 & 3.60 & 2.00 & 3.10 & 10.40 & 3.30 & 0.50 & 0.50 & 1.00 & 0.00025 & 0.004 \\
\hline A6 Ca & 4.20 & 7.30 & 1.80 & 1.00 & 4.20 & 4.00 & 1.30 & 2.60 & 2.00 & 0.0005 & 0.016 \\
\hline $\mathrm{A} 7 \mathrm{Ca}$ & 2.60 & 9.40 & 3.60 & 0.70 & 4.20 & 6.40 & 1.30 & 1.90 & 1.50 & 0.001 & 0.016 \\
\hline $\mathrm{A} 8 \mathrm{Ca}$ & 2.60 & 5.20 & 2.00 & 0.90 & 2.60 & 2.90 & 1.00 & 2.10 & 2.00 & 0.0005 & 0.008 \\
\hline A9 Ca & 6.30 & 8.30 & 1.30 & 2.30 & 10.40 & 4.40 & 1.00 & 1.80 & 0.80 & 0.00025 & 0.008 \\
\hline $\mathrm{A} 10 \mathrm{Ca}$ & 6.30 & 14.60 & 2.30 & 1.80 & 5.20 & 2.90 & 1.30 & 1.30 & 1.00 & 0.0005 & 0.016 \\
\hline \multicolumn{12}{|l|}{ Candida glabrata } \\
\hline $\mathrm{B} 5 \mathrm{Cg}$ & 8.30 & 16.70 & 2.00 & 4.20 & 12.50 & 3.00 & 0.30 & 0.70 & 2.00 & 0.0005 & 0.008 \\
\hline $\mathrm{B} 6 \mathrm{Cg}$ & 5.20 & 10.40 & 2.00 & 20.80 & 41.70 & 2.00 & 0.20 & 0.40 & 2.10 & 0.002 & 0.008 \\
\hline SC 5314-Ca & 2.080 & 6.30 & 3.00 & 1.00 & 1.80 & 1.80 & 1.00 & 1.30 & 1.30 & 0.0005 & 0.016 \\
\hline $\begin{array}{c}\text { ATCC } \\
2001-C g\end{array}$ & 5.20 & 8.30 & 1.60 & 8.30 & 20.80 & 2.50 & 0.50 & 1.30 & 2.50 & 0.00025 & 0.016 \\
\hline ATCC 90028- $\mathrm{Ca}$ & 5.20 & 10.40 & 2.00 & 10.40 & 20.80 & 2.00 & 0.40 & 1.60 & 4.00 & 0.001 & 0.008 \\
\hline
\end{tabular}

Legends: Ca, Candida albicans; $\mathrm{Cg}$, Candida glabrata; SC $5314 \mathrm{Ca}$, reference strain; PiHE, a hydroethanolic extract of Platonia insignis; DCMF, dichloromethane fraction; EAF, ethyl acetate fraction; AMB, amphotericin; FLZ, fluconazole.

Table 3. MIC/MFC geometric means, MIC/MFC ranges, $\mathrm{MIC}_{90}$, and $\mathrm{MFC}$ of 16 clinical isolates of Candida spp. and reference strains for each tested substance.

\begin{tabular}{|c|c|c|c|c|c|c|c|}
\hline \multirow{2}{*}{$\begin{array}{c}\text { Species } \\
\text { (n of Isolates) }\end{array}$} & \multirow{2}{*}{$\begin{array}{c}\text { Antifungal } \\
\text { Agent }\end{array}$} & \multicolumn{3}{|c|}{$\mathrm{MIC} \mathrm{mg/mL}$} & \multicolumn{3}{|c|}{ MFC mg/mL } \\
\hline & & Range & $\begin{array}{c}\text { Geometric } \\
\text { Means }\end{array}$ & $\mathrm{MIC}_{90}$ & Range & $\begin{array}{c}\text { Geometric } \\
\text { Means }\end{array}$ & MFC \\
\hline \multirow{3}{*}{$\begin{array}{l}\text { Candida albicans } \\
\qquad(10)\end{array}$} & PiHE & $1.8-6.30$ & 3.18 & 3.58 & $3.60-14.60$ & 6.45 & 7.44 \\
\hline & DCMF & $0.7-3.10$ & 1.20 & 1.41 & $2.60-10.40$ & 4.78 & 5.42 \\
\hline & EAF & $0.50-1.30$ & 0.98 & 1.07 & $0.50-2.60$ & 1.46 & 1.72 \\
\hline \multirow{3}{*}{ Candida glabrata (6) } & PiHE & $1.60-8.30$ & 3.45 & 4.07 & $2.30-25.00$ & 5.69 & 7.28 \\
\hline & DCMF & $1.8-20.8$ & 3.74 & 5.95 & $3.60-41.70$ & 9.09 & 13.70 \\
\hline & EAF & $0.2-1.00$ & 0.30 & 0.38 & $0.30-2.60$ & 0.54 & 0.68 \\
\hline \multirow{3}{*}{ SC 5314-Ca } & PiHE & $0.40-3.12$ & 1.71 & 2.08 & $4.80-8.6$ & 6.25 & 6.30 \\
\hline & DCMF & $0.70-1.80$ & 0.96 & 1.00 & $1.56-3.12$ & 1.63 & 1.80 \\
\hline & EAF & $0.78-1.56$ & 0.96 & 1.00 & $0.78-2.00$ & 1.21 & 1.30 \\
\hline \multirow{3}{*}{ ATCC 2001-Cg } & PiHE & $3.12-6.30$ & 5.11 & 5.20 & $6.20-12.50$ & 7.93 & 8.30 \\
\hline & DCMF & $6.30-12.50$ & 8.01 & 8.30 & $12.10-25.00$ & 19.79 & 20.8 \\
\hline & EAF & $0.39-0.78$ & 0.49 & 0.50 & $0.78-2.20$ & 1.19 & 1.30 \\
\hline \multirow{3}{*}{ ATCC 90028-Ca } & PiHE & $3.10-6.30$ & 5.08 & 5.20 & $6.20-25.00$ & 9.49 & 10.40 \\
\hline & DCMF & $6.30-12.50$ & 10.17 & 10.40 & $12.10-25.00$ & 19.79 & 20.8 \\
\hline & EAF & 0.10-1.00 & 0.37 & 0.40 & 0.90-2.30 & 1.52 & 1.60 \\
\hline
\end{tabular}

Legends: Ca, Candida albicans; Cg, Candida glabrata; SC $5314 \mathrm{Ca}$, wild-type reference strain; PiHE, Platonia insignis hydroethanolic extract; DCMF, dichloromethane fraction; EAF, ethyl acetate fraction; MIC, minimum inhibitory concentration; and MFC, minimum fungicide concentration.

\subsubsection{Killing Assay}

The time-kill curve assay showed that both the extract and fractions of P. insignis significantly reduced the cellular growth of C. albicans SC 5314 within the first few hours of treatment (Figure 3A). PiHE at MIC, EAF at MIC, and $2 \times$ MIC inhibited more than $50 \%$ growth of Candida spp. after $6 \mathrm{~h}$ of treatment and maintained the reduced cell counts compared to the untreated control, ultimately resulting in a growth reduction greater than $3 \log 10(99.9 \%)$ after $12 \mathrm{~h}$ of treatment, exhibiting a potential fungicidal action. DCMF had an inhibitory effect on C. albicans growth after $24 \mathrm{~h}$ of treatment compared to the control, with more than a $90 \%$ reduction rate. In the case of $C$. glabrata (Figure 3B), the 
PiHE showed growth reduction greater than $69 \%$ at $6 \mathrm{~h}$ of treatment and more than $90 \%$ inhibition compared to the untreated control at $12 \mathrm{~h}$ of treatment, reaching $99.9 \%$ (3 $\log 10)$ inhibition after $24 \mathrm{~h}$ of treatment. EAF showed a significant inhibitory action $(p<0.05)$, being able to reduce the growth of C. glabrata by more than $84 \%$ after $6 \mathrm{~h}$ of treatment and more than $90 \%$ in $9 \mathrm{~h}$ of treatment, and reached $99.9 \%$ (3 $\log 10$ ) inhibition after $12 \mathrm{~h}$ of treatment. DCMF only reduced the growth of C. glabrata at $24 \mathrm{~h}$ of treatment, reaching about a $90 \%$ reduction; however, it was not able to totally eliminate the yeast cells. In conclusion, EAF showed stronger antifungal activity than PiHE and DCMF.
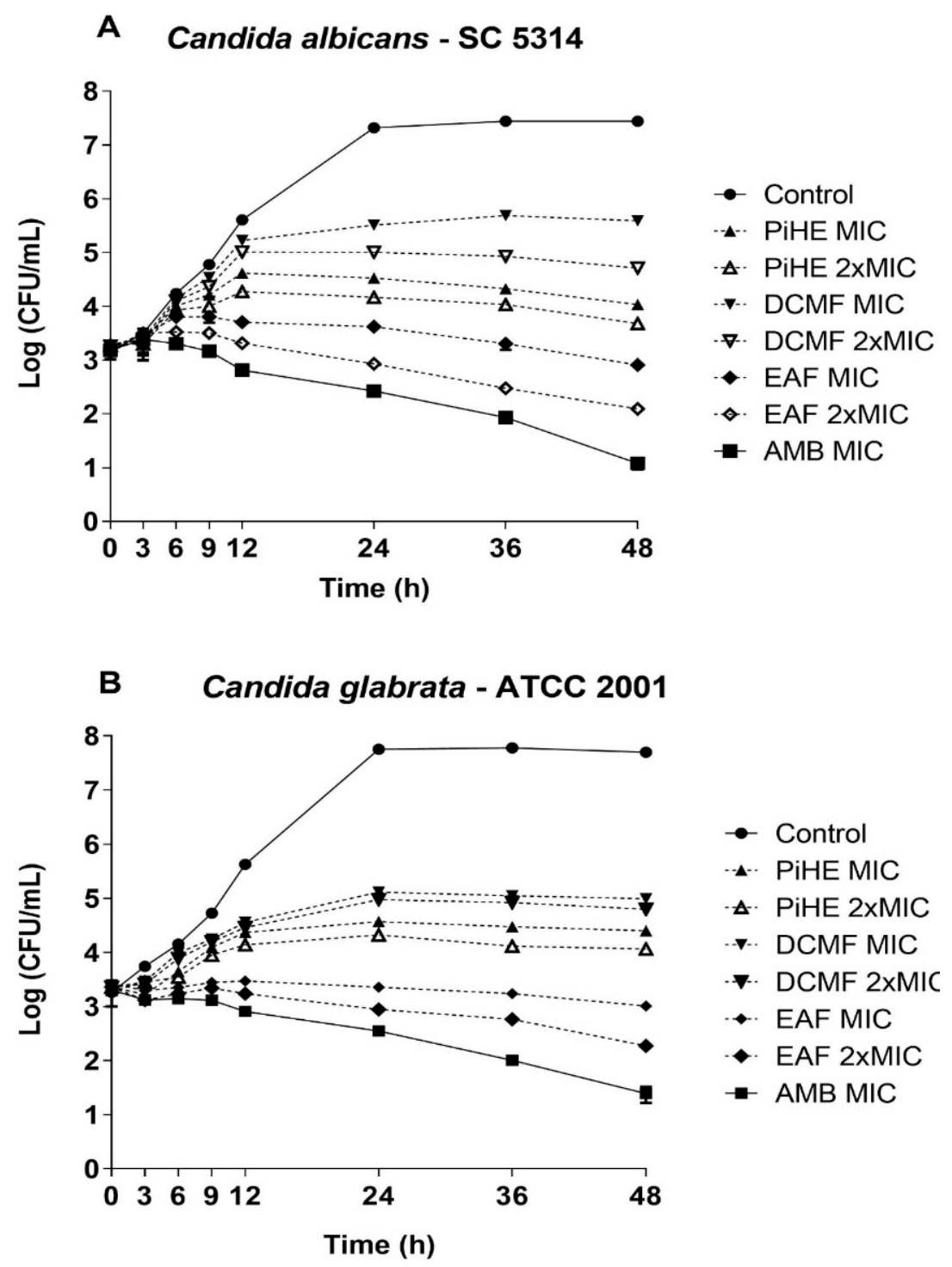

Figure 3. Time-kill curve for C. albicans SC 5314 (A) and C. glabrata ATCC 2001 (B) in the presence and absence of the Platonia insignis hydroethanolic extract and fractions. After different treatment times $(0,3,6,9,12,24,36$, and $48 \mathrm{~h})$ at $37^{\circ} \mathrm{C}$ for PiHE, DCMF, EAF (MIC and $2 \times$ MIC), and AMB (MIC), $20 \mu \mathrm{L}$ samples were withdrawn and subjected to serial dilutions before seeding on the Sabouraud Dextrose Agar (SDA) for counting colony-forming units (CFU)/mL. Data are presented as means of three biological replicates \pm standard deviation and were analyzed at each time in comparison to the control samples. Symbols represent the quantification of colony-forming units grown at each tested time evaluated for each treatment. 


\subsection{Antivirulence Activities}

\subsubsection{Effect of PiHE, DCMF, and EAF on Cell Adhesion}

The cell adhesion of $C$. albicans SC 531 cells was inhibited by EAF at $\frac{1}{2} \times \operatorname{MIC}(p<0.0001$, Figure 4A). Both PiHE and EAF inhibited C. glabrata adhesion at $\frac{1}{2} \times$ MIC concentration (Figure 4B). EAF showed better anti-adherence activity compared to PiHE against both the tested strains $(p<0.0001$; Figure 4$)$. The anti-adherence activity of EAF was even better than that of AMB against $C$. albicans $(p<0.0001$; Figure 4A).
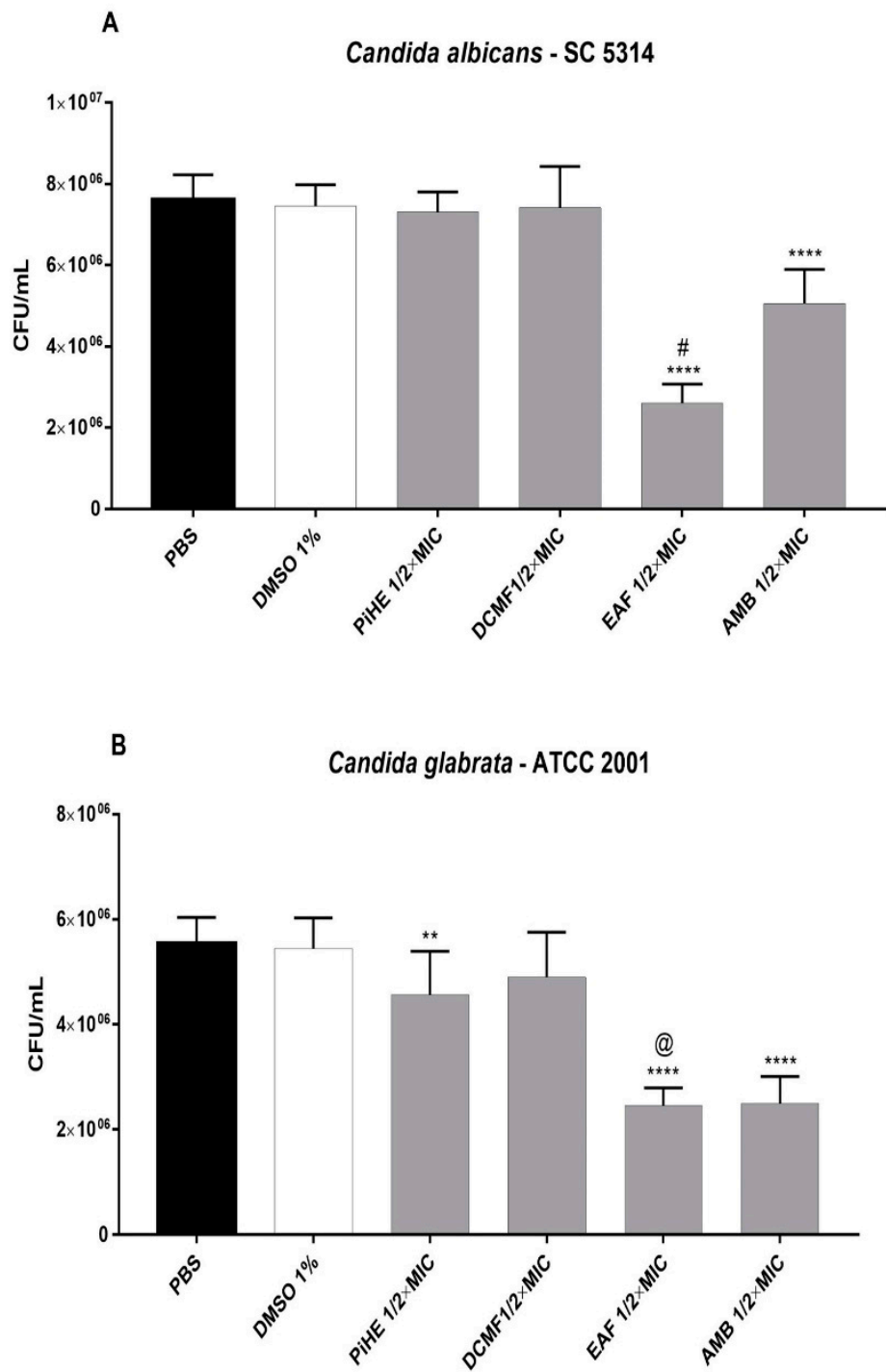

Figure 4. Effect of the hydroethanolic extract and fractions of P. insignis on the adhesion property of C. albicans (A) and C. glabrata (B). Cells were treated for $1.5 \mathrm{~h}$ and adhesion was analyzed for the reference strains in terms of CFU/mL. PBS, inoculum diluent $\left(1 \times 10^{7}\right.$ cells $\left./ \mathrm{mL}\right)$, and $1 \%$ DMSO were used as controls. Data were analyzed in relation to the PBS control by an analysis of variance with Tukey's post-test, considering $p<0.05$, and are represented as the mean \pm standard deviation. $\left.{ }^{* *}\right) p<0.01 ;\left({ }^{* * *}\right) p<0.0001$; (\#) $p<0.0001$ with respect to PiHE, DCMF, and AMB; (@) $p<0.0001$ with respect to PIHE and DCMF. AMB, amphotericin B; FLZ, fluconazole; PiHE, hydroethanolic extract of P. insignis; DCMF, dichloromethane fraction; EAF, ethyl acetate fraction. The tests were performed in quadruplicate. 


\subsubsection{Effects of PiHE, DCMF, and EAF on Biofilm Formation and Pre-Formed Biofilms}

PiHE, DCMF, and EAF showed anti-biofilm activity on biofilm development, as well as on mature biofilms (Figures 5 and 6). PiHE, DCMF, and EAF significantly reduced $(p<0.05)$ biofilm formation for $C$. albicans and C. glabrata and also had an inhibitory effect on pre-formed biofilms, compared to the control. EAF reduced C. albicans biofilm formation more than DCMF or PiHE (Figure 5A). PiHE and EAF were more effective in achieving the mature biofilm disruption of C. glabrata (Figure 5D). The anti-biofilm activity of the extracts was confirmed by biomass reduction analyses (Figure 6A-D) and by a metabolic activity assay (Figure 6E-H). EAF was highly potent in decreasing the viability (reduction $>90 \%$ ) of the mature biofilm for both the reference strains.
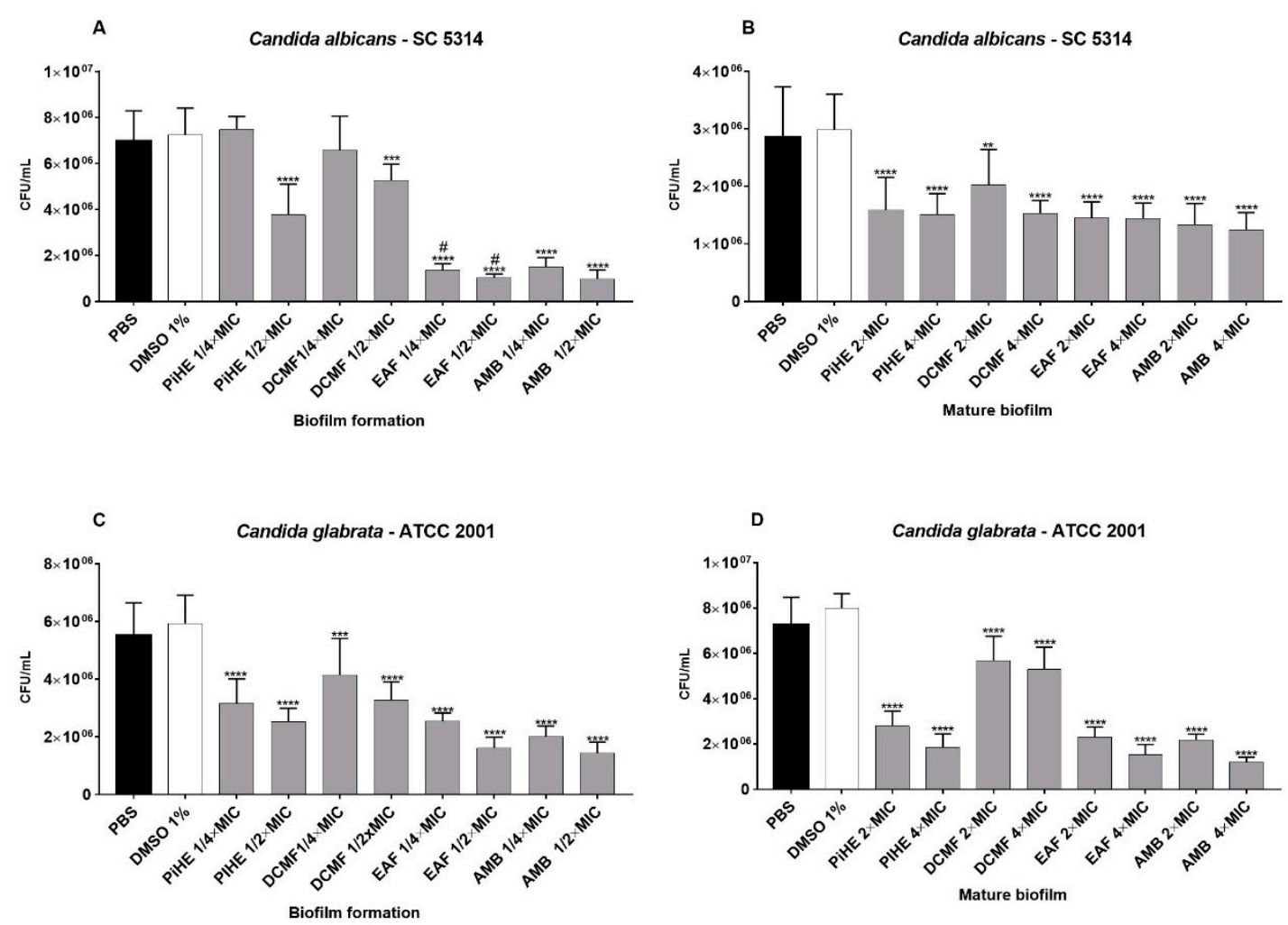

Figure 5. Effect of the P. insignis extract and fractions on C. albicans SC 5314 and C. glabrata ATCC 2001 biofilms. Biofilm formation and mature biofilms are expressed as CFU/mL (A-D). Results were compared to the vehicle control group (1\% DMSO), positive control group (amphotericin $\frac{1}{2}$ MIC, $\frac{1}{4}$ MIC, $2 \times$ MIC, $4 \times$ MIC) and negative control (PBS). Data are represented as the means of biological triplicates \pm standard deviation and were analyzed by ANOVA, followed by Tukey's post-test, with the significance of $p<0.05$. 

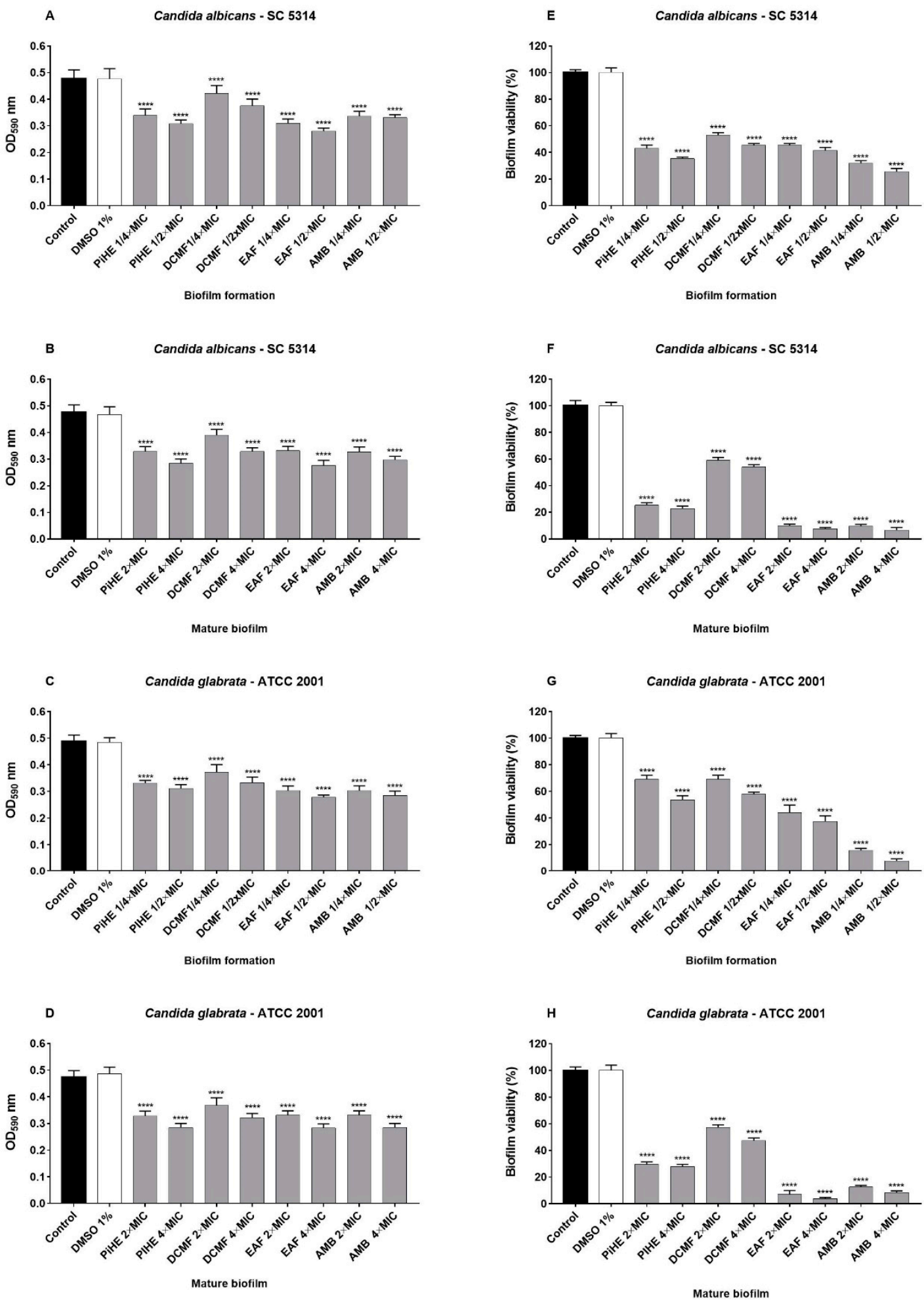

Figure 6. Effect of the P. insignis extract and fractions on C. albicans SC 5314 and C. glabrata ATCC 2001 biofilm formation and mature biofilm inhibition. Biofilm formation and mature biofilms were analyzed by measuring the absorbance at $590 \mathrm{~nm}(\mathbf{A}-\mathbf{D})$ and percent viability (E-H). Metabolic activity was evaluated by the MTT reduction assay. Results were compared to the vehicle control group (1\% DMSO), positive control group (amphotericin $\frac{1}{2} \mathrm{MIC}, \frac{1}{4} \mathrm{MIC}, 2 \times \mathrm{MIC}, 4 \times \mathrm{MIC}$ ), and negative control (PBS). Data are represented as the mean \pm standard deviation for three independent experiments with a significance of $p<0.05$, and were analyzed by ANOVA, followed by Tukey's post-test. ${ }^{*} p<0.05$. 


\subsection{Evaluation of Mitochondrial Membrane Potential by Flow Cytometry}

The effect of PiHE, DCMF, and EAF on the mitochondrial membrane potential of $C$. albicans and C. glabrata cells was analyzed by flow cytometry. Untreated cells showed high fluorescence emission intensities due to the incorporation of Rhodamine 123 (Rho 123), whereas, upon treatment with the extracts, the fluorescence intensity was significantly reduced $(p<0.05)$. The reduction in the fluorescence intensity had a positive variation index (VI), indicating the depolarization of the mitochondrial membrane of $C$. albicans and C. glabrata (Figure 7). The relative fluorescence intensity in C. albicans cells was reduced to $2.67 \%$ and $2.65 \%$ (MIC and $2 \times$ MIC, respectively) in the presence of $\mathrm{PiHE}, 88.13 \%$ and $44.84 \%$ (MIC and $2 \times$ MIC, respectively) in the presence of DCMF, and $17.90 \%$ and $8.85 \%$ (MIC and $2 \times$ MIC, respectively) with EAF.

\begin{tabular}{|c|c|c|c|c|c|c|c|}
\hline & \multicolumn{7}{|c|}{$\begin{array}{l}\text { Mitoch ondrial membrane poten tial } \\
\text { Relative fluorescence intensity (\%) (Mean } \pm \text { Standard deviation) }\end{array}$} \\
\hline \multirow{2}{*}{ Strains } & \multirow{2}{*}{ Untreated } & \multicolumn{2}{|c|}{ PiHE } & \multicolumn{2}{|c|}{ DCMF } & \multicolumn{2}{|c|}{ EAF } \\
\hline & & $1 \times \mathbb{M C}$ & $2 \times M \mathbb{M C}$ & $1 \times \mathrm{MC}$ & $2 \times \mathrm{MIC}$ & $1 \times \mathrm{MIC}$ & $2 \times$ MIC \\
\hline $\begin{array}{l}\text { C. albianns } \\
\text { SC } 5314\end{array}$ & $100.0 \pm 7.05$ & $2.67 \pm 0.14^{*}$ & $2.65 \pm 0.34^{*}$ & $88.13=1.46^{*}$ & $44.84 \pm 3.75^{*}$ & $17.90 \pm 0.85^{*}$ & $8.85 \pm 0.62 *$ \\
\hline $\begin{array}{l}\text { C. glabrata } \\
\text { ATCC } 2001\end{array}$ & $100.0 \pm 4.46$ & $14.5 \pm 5.27^{*}$ & $8.98 \pm 0.79 *$ & $30.90 \pm 3.75 *$ & $11.59=1.48^{*}$ & $30.93 \pm 0.88^{*}$ & $20.75 \pm 0.60 *$ \\
\hline
\end{tabular}

B

C. albicans - SC 5314

C. glabrata-ATCC 2001
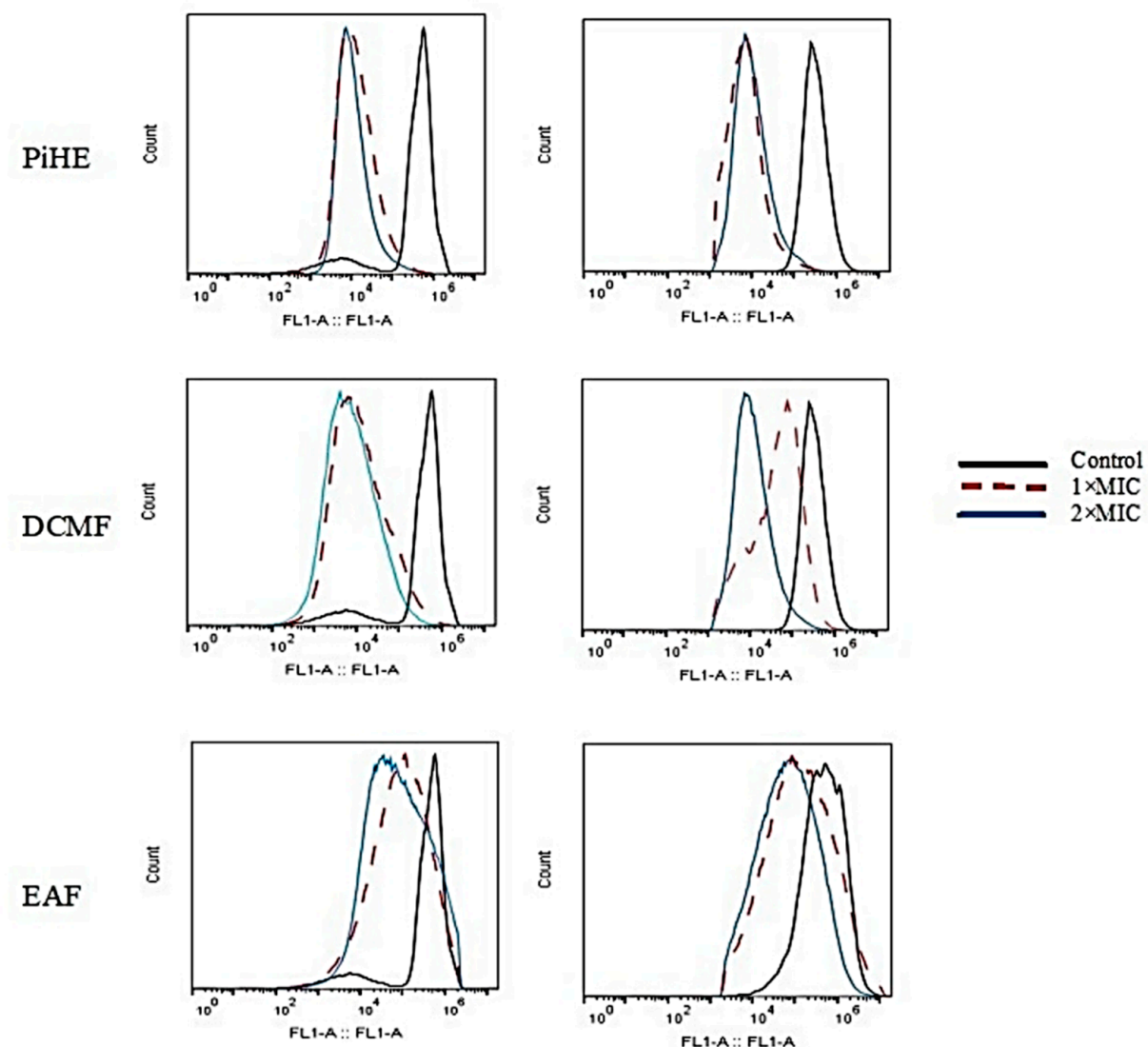

Figure 7. The Platonia insignis extract and fractions reduced the mitochondrial integrity of C. albicans and C. glabrata cells after $24 \mathrm{~h}$ of treatment. Data are shown as relative fluorescence intensity (A) and histogram (B) plots. Data were analyzed by ANOVA, followed by Tukey's post-test, and statistical differences are represented by an asterisk, ${ }^{*} p<0.05$. MIC, minimum inhibitory concentration; PiHE, hydroethanolic extract of $P$. insignis; DCMF, dichloromethane fraction; and EAF, ethyl acetate fraction. 
For C. glabrata, a reduction of $14.85 \%$ (MIC) and $8.98 \%(2 \times \mathrm{MIC})$ in the relative fluorescence intensities was seen when treated with PiHE, while in the presence of DCMF, it was $30.90 \%$ and $11.59 \%$ for MIC and $2 \times$ MIC, respectively. Finally, when treated with EAF, the relative fluorescence intensity reductions were $30.93 \%$ and $20.75 \%$, respectively (Figure 7).

\subsection{Evaluation of Lysosomal Membrane Integrity upon Treatment with PiHE, DCMF, and EAF}

The effects of PiHE, DCMF, and EAF on the Candida cells were analyzed by the evaluation of the lysosomal membrane integrity. Untreated cells showed a strong fluorescence emission, confirming that these cells had intact lysosomes (Figure 8). Treatment with PiHE, DCMF, and EAF compromised the Candida cells' lysosomal membrane, due to the observed reduction in the fluorescence intensity emitted when compared to the control group. Treatment with PiHE reduced the relative intensity in C. albicans cells to $45.03 \%$ (MIC) and $34.8 \%(2 \times$ MIC) and in C. glabrata cells to $25.35 \%$ (MIC) and $13.23 \%(2 \times$ MIC). DCMF reduced the fluorescence intensity in C. albicans to $53.04 \%$ (MIC) and $64.40 \%$ and to $40.79 \%$ $(2 \times \mathrm{MIC})$ in C. glabrata, respectively. EAF showed a reduction in the fluorescence intensity greater than $90 \%$ at both concentrations tested against C. albicans. In the case of C. glabrata, the reduction in the fluorescence intensity was between $83 \%$ and $95 \%$ (Figure 8 ).

\begin{tabular}{|c|c|c|c|c|c|c|c|}
\hline $\mathbf{A}$ & \multicolumn{7}{|c|}{ Lysosomal membrane stability } \\
\hline \multirow{2}{*}{ Strains } & & \multicolumn{2}{|c|}{ PHE } & \multicolumn{2}{|c|}{ DCMF } & \multicolumn{2}{|c|}{ EAF } \\
\hline & Untreated & $1 \times$ MIC & $2 \times$ MIC & $1 \times$ MIC & $2 \times \mathrm{MIC}$ & $1 \times M C$ & $2 \times \mathrm{MC}$ \\
\hline $\begin{array}{l}\text { C. albiants } \\
\text { SC } 5314\end{array}$ & $100.0 \pm 4.69$ & $45.03 \pm 3.48^{*}$ & $34.80 \pm 2.26^{*}$ & $53.04 \pm 4.84^{*}$ & $64.40 \pm 6.30^{*}$ & $5.90 \pm 0.43^{*}$ & $3.52 \pm 0.11^{*}$ \\
\hline $\begin{array}{l}\text { C. glabrata } \\
\text { ATCC } 2001\end{array}$ & $100.0 \pm 5.45$ & $25.35 \pm 2.40^{*}$ & $1323 \pm 1.47^{*}$ & $84.85 \pm 10.86$ & $40.79 \pm 3.22^{*}$ & $16.76 \pm 3.58^{\star}$ & $4.95 \pm 0.52^{*}$ \\
\hline
\end{tabular}
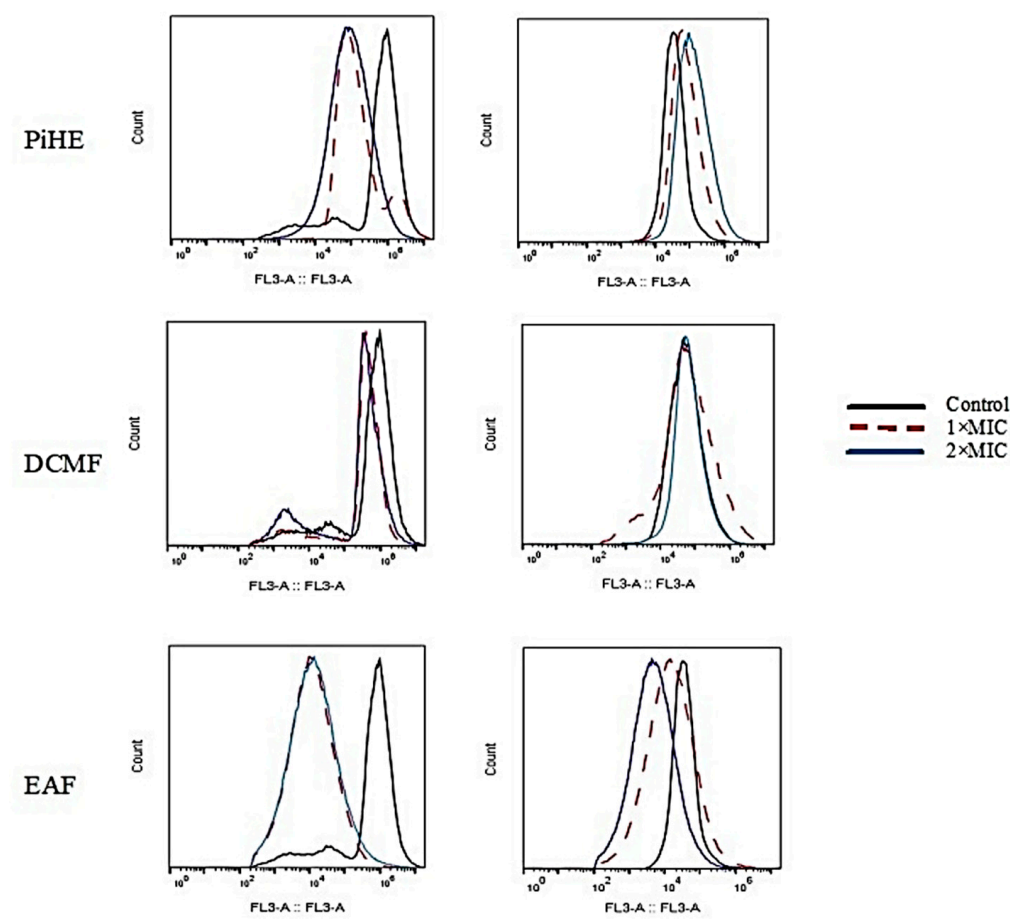

Figure 8. The P. insignis extract and fractions reduced the lysosomal integrity of C. albicans and C. glabrata cells after $24 \mathrm{~h}$ of treatment. Data are shown as the relative fluorescence intensity (A) and histograms (B). Data were analyzed by ANOVA, followed by Tukey's post-test, and statistical differences are represented by an asterisk. ${ }^{*} p<0.05$. MIC, minimum inhibitory concentration; PiHE, hydroethanolic extract of P. insignis; DCMF, dichloromethane fraction; and EAF, ethyl acetate fraction. 


\subsection{Cellular Cytotoxicity Assay}

The cytotoxic effects of the P. insignis extract and fractions are shown in Figure 9. Even at high concentrations, PiHE and EAF did not show cellular toxicity on RAW 264.7 cells, (Figure 9A,C). PiHE and EAF also displayed low hemolytic activity (Figure 9D). The dichloromethane fraction (DCMF) exhibited dose-dependent cytotoxic activity as the viability was less than $50 \%$ at a $10 \mathrm{mg} / \mathrm{mL}$ concentration. DCMF also showed elevated hemolytic activity above a $5 \mathrm{mg} / \mathrm{mL}$ concentration (Figure 9B,D).
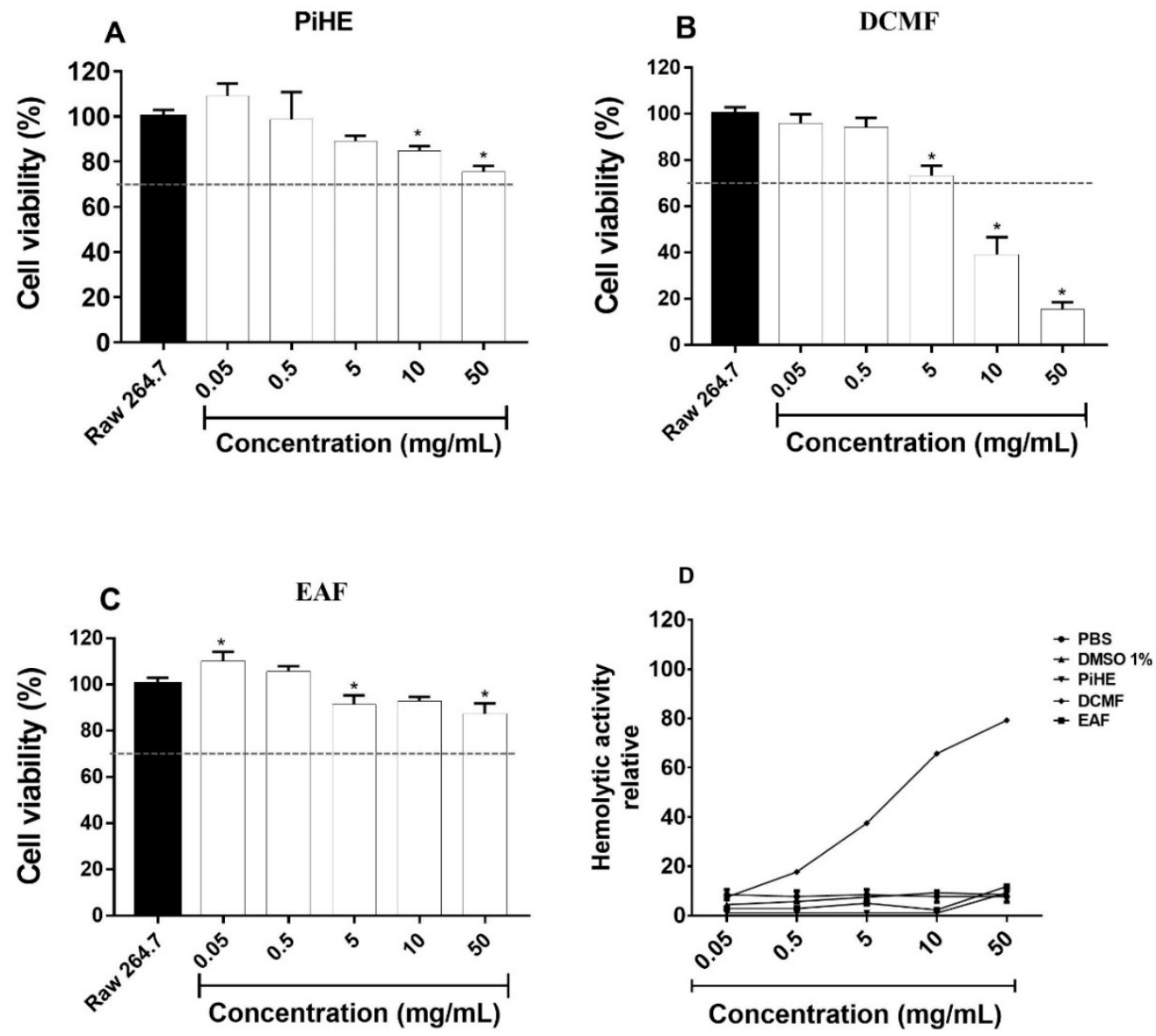

Figure 9. Effect of the P. insignis extract and fractions on RAW 264.7 cell viability (A-C) and on the hemolytic activity of sheep erythrocytes (D). Cells at the amount of $1 \times 10^{6} / \mathrm{mL}$ were used in assays. The effects of PiHE, DCMF, and EAF on RAW 264.7 cells are shown, and viability above $70 \%$ was considered non-cytotoxic according to the ISO 10993-5 (2009) when compared to the untreated control (A-C). The percent hemolytic activity was compared to Triton X-100, as the hemolysis control (D). Triton X hemolytic activity was considered as $100 \%$ for data analysis. Data were analyzed by ANOVA with Tukey's post-test, with ${ }^{*} p<0.05$.

\section{Discussion}

With the increase in antibiotic-resistant Candida species, traditional antifungals are no longer effective in treating candidiasis. Therefore, it is highly necessary to identify new molecules that are non-toxic and more effective for developing therapies to treat Candida infections [8]. Platonia insignis (bacurizeiro) is an arboreal species native to the Brazilian Amazon and in particular, to the States of Maranhão and Piauí, where this species is found spontaneously. Its fruits are known for their pleasant taste and aroma and are highly appreciated by the Amazonian people [15]. Some studies have reported the biological activity of different extracts of $P$. insignis and the chemical components, such as Garcinielliptone FC, responsible for the biological activity, have already been isolated and 
identified $[12,13,16]$. However, the ethnopharmacological use of $P$. insignis is related to the use of the extracts of its seeds, bark, or fruit pulp because of its ability to heal, anti-inflammatory effects, leishmanicidal agents, antioxidants, and cytotoxic activities. This is the first study to report the antifungal activity of a hydroethanolic extract of $P$. insignis leaves and its fractions and thus is a pioneering investigation in the field of developing novel therapies to treat Candida infections.

In the present study, we evaluated the in vitro antifungal potential of a hydroethanolic extract of $P$. insignis leaves and the effects of the dichloromethane and ethyl acetate fractions against 16 clinical isolates of Candida spp. and reference strains C. albicans SC 5314 and C. glabrata ATCC 2001. Furthermore, we analyzed the complete phytochemical profile of its compounds by LC-ESI-IT-MS.

For a plant extract or fraction to have fungicidal potential, the MFC/MIC ratio must be less than 4 [17]. PiHE and its fractions showed an antifungal effect against the Candida isolates. PiHE had a fungicidal effect on isolates, with MICs ranging from 1.8 to $6.3 \mathrm{mg} / \mathrm{mL}$ against C. albicans and 1.6 to $8.3 \mathrm{mg} / \mathrm{mL}$ against C. glabrata. Among the tested fractions, EAF showed better antifungal activity, with a fungicidal effect on the isolates with relatively low MIC and MFC values. This anti-Candida action is mainly attributed to the presence of phytocompounds present in the extract and fractions evaluated. Fourteen compounds were identified by LC-ESI-IT-MS, among which were the glycosylated flavonoids derived from quercetin and myricetin, such as ononin and fukugentin. This chemical profile is completely new and different compared to those already described in the literature for extracts of $P$. insignis seeds that mainly comprise fatty acids, terpenes, xanthones, and phenolics as the major constituents. In addition, we found new compounds that have not been described as antifungal agents in large quantities in EAF, which explains the better antifungal activity of this fraction.

Though some pharmacological properties of $P$. insignis-derived compounds are known, their effects on Candida adhesion and biofilm formation, considered major concerns of the health care industry, have not been studied until now. PiHE and its fraction were able to inhibit the initial adhesion of C. albicans SC 5314 and C. glabrata ATCC 2001. EAF significantly inhibited the adhesion capacity of Candida strains at all tested concentrations and also at very low concentrations, especially in C. glabrata cells. These results are relevant since the first step in biofilm formation is the adhesion capacity, a process dependent on several adhesin proteins present in the Candida cells and which promotes the attachment to epithelia, other microorganisms, or abiotic substrates [18].

Candida spp. are known to form highly organized biofilms, especially in internal catheters and other prosthetic devices [19]. Furthermore, biofilms are known to be highly resistant to antifungals, which is a major hurdle in establishing an effective treatment [20,21]. Therefore, PiHE and its fraction are potential candidates for the development of effective antifungal drugs because they inhibited the formation of biofilms and significantly decreased the metabolic activity of preformed biofilms in the tested strains. We observed that the extract and fractions had a promising effect against preformed biofilms. Our results showed that there was a significant reduction in CFU/mL counts, and this was corroborated by crystal violet analysis $(p<0.0001)$ for both strains tested. These results were even more significant as EAF showed an inhibitory effect on the metabolic activity of the biofilms, exhibiting 90\% inhibition for C. albicans and 96\% inhibition for C. glabrata. These data suggest that the compounds have potent anti-biofilm activity and can be used as alternatives to anti-fungal drugs. Candida species have emerged as deadly human pathogens, particularly for immunocompromised individuals, because of the associated high mortality rates. Therefore, PiHE and EAF are promising new compounds for the development of drugs and phytotherapy with antifungal and anti-biofilm properties.

Surprisingly, extracts and fractions had a more pronounced effect on mature biofilm $(48 \mathrm{~h})$ than on biofilms in formation. The observation of this phenomenon may be due to the formation dynamics and the composition of biofilms in these different stages. In the early stages of biofilm formation, many planktonic cells are present, and the molecular structures and water content are different from those in a mature biofilm stage $(48 \mathrm{~h})$, which may have interfered with the mechanism of action and the efficiency of the extract and fractions of $P$. insignis. In this way, the extracts could be acting on extracellular matrix components, which are more present in mature biofilms. Similar results were 
obtained by Teodoro et al. [22] when studying the effects of a Buchenavia tomentosa acetone fraction on Candida biofilms.

Natural compound identification with anti-biofilm or anti-fungal activity against Candida is a difficult task. Recently, only a few therapeutic agents have demonstrated activities against fungal biofilms in vitro and/or in vivo [23]. Therefore, it is important to discover new anti-biofilm molecules. A previous study characterized 35 pharmacologically active compounds and verified that only one had an effect on Candida albicans biofilms and was not cytotoxic [24]. Alalwan et al. [25] performed different experiments with curcumin and found that this substance interferes with the adhesion of C. albicans SC5314 to denture materials. Teodoro et al. [22] demonstrated that an acetone fraction from a Buchenavia tomentosa extract had the ability to inhibit C. albicans ATCC 18804 and C. albicans SC 5314 adherence and to disrupt $48 \mathrm{~h}$ biofilm. However, they also verified that the acetone fraction and gallic acid showed slight to moderate toxicity to Vero cells.

This is the first report showing potent anti-Candida and anti-virulence activity for PiHE and EAF, and in addition, both of them were non-toxic towards keratinocytes, which makes PiHE and EAF ideal candidates for the treatment of candidiasis. When treated with higher concentrations of PiHE, RAW 264.7 cells had more than $70 \%$ viability, while EAF was not cytotoxic at any concentration tested. PiHE and EAF do not cause hemolysis, which also constitutes a fundamental characteristic of an ideal anti-fungal drug.

Furthermore, we decided to verify the action of the extract and fractions on fungal cells. The extracts triggered a perturbation of the mitochondrial membrane, which caused membrane depolarization. Therefore, the treatment of yeast cells with extracts altered the respiratory functions of the mitochondrial membrane and prevented Rho 123 from accumulating in the mitochondrial membrane [26]. The alteration of $\Delta \Psi \mathrm{m}$ can cause a collapse of the membrane and would lead to a transient opening of pores in the membrane, releasing pro-apoptotic factors in the cytosol $[27,28]$. This, in part, provides a possible explanation for the antifungal potential of the extracts in relation to the number of flavonoid derivatives present in them. These also exhibited the presence of pro-oxidant factors [29], increasing intracellular free radical levels and causing damage in the mitochondrial membrane [27].

We observed that PiHE, DCMF, and EAF also damaged the lysosomal membrane in fungal cells. Lysosomes are acidic organelles that contain hydrolytic enzymes, which are involved in various cellular processes, such as post-translational protein maturation, receptor degradation, and the extracellular release of active enzymes [30]. Lysosomal membrane rupture causes release into the cytosol of cathepsin $\mathrm{D}$ and cysteine, which are classes of lysosomal proteases directly responsible for the induction of apoptosis [30]. The P. insignis extract and fractions caused the rupture of the lysosomal membrane of the treated cells, leading to a loss of lysosomal $\mathrm{pH}$ and the subsequent leakage of Acridine Orange (AO) in the cytosol [31], causing an increase in green fluorescence when compared to the untreated cells.

The P. insignis extract and fractions were not cytotoxic, so we think that their constituents probably interact with a specific component of the fungal membrane, such as ergosterol, or with one of the intermediates from the complex cell membrane synthesis pathway, which, in any case, would lead to a reduction of ergosterol. This, in turn, would lead to the disruption or opening of pores in the plasma membrane, resulting in the death of fungal cells.

Given the results obtained, in vitro, bioinformatics, and murine VVC model studies are underway to confirm the antifungal activity of the compounds found in EAF.

\section{Materials and Methods}

\subsection{Plant Material: Collection, Identification, and Extraction}

Plant material (leaves) was collected between May and June 2017 in São Luís, Maranhão, Brazil (W44 $13^{\circ} 35.1^{\prime \prime} \mathrm{S} 2^{\circ} 31^{\prime} 38.2^{\prime \prime}$ ). The species were identified and cataloged at Maranhão Herbarium, Center of Biological and Health Sciences from the Federal University of Maranhão, under the voucher 
specimen number 9722 identified by Prof. Eduardo B. de Almeida Jr. Extracts were prepared in the Chemistry Laboratory of Ceuma University. The leaves were sanitized and dried at $28^{\circ} \mathrm{C}$ for seven days and then pulverized in a slicer (Te-651/2, Tecnal ${ }^{\circledR}$, Piracicaba, SP, Brazil). Then, $200 \mathrm{~g}$ of plant material was $1 / 6(\mathrm{~m} / \mathrm{v})$ diluted in $70 \%$ ethanol and macerated for five days at $28{ }^{\circ} \mathrm{C}$ with occasional stirring, and solvent was exchanged every $24 \mathrm{~h}$. The extract was filtered, and the supernatant was concentrated in a rotary evaporator under reduced pressure at $40{ }^{\circ} \mathrm{C}$ (Quimis ${ }^{\circledR}$, Modelo BOD Q-315M).

The hydroethanolic extract of P. insignis (PiHE) $\left(98 \%\right.$ yield) was lyophilized (Liotop ${ }^{\circledR}$, model L101); packed in a sterile, hermetically-sealed amber glass bottle; and stored at $-20^{\circ} \mathrm{C}$ until further use. The extract was sequentially subjected to liquid-liquid partition with dichloromethane (DCM) (Dinamica, SP), followed by ethyl acetate (EAT) (Dinamica, SP). PiHE (10 g) was suspended in $100 \mathrm{~mL}$ of water:methanol solution (8:2), followed by four liquid-liquid extractions with DCM and then, with EAT, resulting in two fractions: a dichloromethane fraction (DCMF) and an ethyl acetate fraction (EAF). The obtained fractions were concentrated, lyophilized, and stored at $-20^{\circ} \mathrm{C}$ until further use.

\subsection{Chemical Analyses}

\subsubsection{HPLC Fingerprint Analysis}

Experiments for phytochemical fingerprint analysis were carried out using a Thermo Scientific ${ }^{\circledR}$ LCQ Fleet mass spectrometer system (Thermo Fisher Scientific, Waltham, MA, USA). The chromatographic separation was performed on Kinetex ${ }^{\circledR} \mathrm{C} 18(2.1 \times 100 \mathrm{~mm}, 100 \mathrm{~A}$, and $5 \mu \mathrm{m})$. The mobile phases used were $0.1 \%$ formic acid in water (A) and acetonitrile $+0.1 \%$ formic acid (B) added to $0.1 \%$ formic acid in an exploratory gradient starting with $10 \%$ to $100 \%$ B in $20 \mathrm{~min}$ at a flow rate of $1.0 \mathrm{~mL} / \mathrm{min}$. The sample was injected into the mass spectrometer from the HPLC system, where the sample was analysed online by ESI-MS in negative mode with an associated UV detector. The column temperature was maintained at $25^{\circ} \mathrm{C}$. The flow rate was $1 \mathrm{~mL} / \mathrm{min}$, and the online UV spectrum was monitored at the wavelength of $254 \mathrm{~nm}$.

\subsubsection{ESI-MS/MS Analysis}

The ESI-MS/MS analysis was carried out using a Fleet LCQ mass spectrometer from Thermo Scientific ${ }^{\circledR}$ equipped with an ESI source operating in Auto-MSn mode to obtain fragmentation. The negative ionization mode was applied, and the optimized instrument settings were set as follows: The sample was ionized with an ESI source and fragmentations were obtained in multiple stages $\left(\mathrm{MS}^{\mathrm{n}}\right)$ in an ion trap (IT)-type interface. All the spectra were generated and analysed in negative mode. The experimental conditions were as follows: capillary voltage, $-35 \mathrm{~V}$; spray voltage, $-5000 \mathrm{~V}$; capillary temperature, $350{ }^{\circ} \mathrm{C}$; carrier gas, $\mathrm{N}_{2}$; and flow, 60 (arbitrary units). The track acquisition was set at $m / z$ 100-2000, with two or more sweep events performed simultaneously in the spectrum. All data acquisition and analysis were performed using the Thermo Xcalibur ChemStation (Thermo Fisher Scientific).

\subsection{Antifungal Assays}

\subsubsection{Candida Strains, Growth Conditions, and Inoculum Preparation}

Sixteen clinical vaginal isolates of Candida spp. were used in this study. Out of 16, 10 were Candida albicans isolates and 6 were Candida glabrata isolates. Two reference strains from the American Type Culture Collection (ATCC), C. albicans ATCC 90028 and C. glabrata ATCC 2001, and one Candida albicans wild-type strain from the Spain Collection (SC5314) were included as controls in the experiments. Clinical vaginal isolates were isolated in accordance with the Declaration of Helsinki, and the protocol was approved by the University Ceuma Ethics Committee (CEP/UNICEUMA $\mathrm{N}:$ 813.402/2014). Isolates were deposited in the collection of the Applied Microbiology Laboratory of Ceuma University São Luís-Ma, Brazil. All subjects gave their informed consent for inclusion 
before they participated in the research. All Candida isolates were identified by multiplex PCR. Reference strains were kindly donated by the São Paulo State University, Araraquara Dental School, São Paulo, Brazil.

For experiments, isolates were reactivated in Sabouraud Dextrose Agar (SDA; Kasvi, Italy) for $24 \mathrm{~h}$ at $37^{\circ} \mathrm{C}$. The inoculum was prepared in $\mathrm{NaCl}$ solution $(0.85 \%)$ from $24 \mathrm{~h}$-grown colonies and adjusted spectrophotometrically (Global Trade Technology) at a wavelength of $530 \mathrm{~nm}$ for a cell density equivalent to McFarland scale 0.5. For microdilution tests, the suspension was diluted in RPMI 1640, with glutamine, without bicarbonate (Sigma-Aldrich, St. Louis, MO, USA), pH 7.0, and buffered with MOPS (Morpholinepropanesulfonic acid, Sigma Chemical, St. Louis, MO, USA) at the concentration of $1 \times 10^{3}$ to $5 \times 10^{3} \mathrm{CFU} / \mathrm{mL}[32]$.

\subsubsection{Determination of the Minimum Inhibitory Concentration (MIC)}

The minimal inhibitory concentration (MIC) was determined by a microdilution test [33]. Fluconazole (FLZ) and Amphotericin B (AMB) (Sigma-Aldrich, São Paulo, Brazil) were used as controls. PiHE and its fractions $(200 \mathrm{mg} / \mathrm{mL}$ ) were dissolved in $20 \%$ DMSO (Dimethylsulfoxide, Merck) and then diluted in RPMI-1640-MOPS to $0.024-100 \mathrm{mg} / \mathrm{mL}$. FLZ was diluted in RPMI-MOPS to $0.125-256 \mu \mathrm{g} / \mathrm{mL}$ and AMB to $0.0313-16 \mu \mathrm{g} / \mathrm{mL}$. RPMI-1640, without the antifungal extract, was used as the negative control in growth assays and $20 \% \mathrm{DMSO}(\mathrm{v} / \mathrm{v})$ was used as the vehicle control. Inoculum $(100 \mu \mathrm{L})$ plus extracts or antifungals $(100 \mu \mathrm{L})$ were incubated for $48 \mathrm{~h}$ at $35^{\circ} \mathrm{C}$. Results were analyzed visually and in a microplate reader at a $540 \mathrm{~nm}$ wavelength (Thermo Plate) [33]. MIC was defined as the lowest concentration of extract, fractions, FLZ, and AMB at which no visible growth was detected. In all experiments, the absorbance values obtained from wells containing extracts, fractions, or antifungals plus medium and inoculum were subtracted from those obtained from wells containing only extract or fractions plus medium. The percent growth inhibition for Candida spp. was determined using the formula described below:

$$
\% \text { Inhibition }=\frac{A c-A t}{A c} \times 100
$$

where $A c$ is the control absorbance and $A t$ is the test absorbance. All the tests were performed as biological triplicates.

\subsubsection{Determination of the Minimum Fungicide Concentration (MFC)}

To determine the MFC value, $10 \mu \mathrm{L}$ aliquots from the microplate wells that had concentrations above the MIC were sub-cultivated on SDA Petri dishes and incubated at $37^{\circ} \mathrm{C}$, for $24-48 \mathrm{~h}$. MFC was defined as the lowest concentration of the extract which showed no colonies on the culture medium surface [32]. The MFC/MIC ratio was calculated to determine if substances had fungistatic (MFC/MIC $>4$ ) or fungicidal (MFC/MIC < 4) action [17,34]. MFC assays were performed in biological triplicates.

\subsubsection{Time-Kill Assay}

C. albicans SC 5314 and C. glabrata ATCC 2001 standard strains were used to establish the time-kill curve. Assays were performed according to the previously published protocol in 96 well-plates, with some modifications [35]. The standard inoculum was diluted in RPMI 1640 to a final concentration of $5 \times 10^{3} \mathrm{CFU} / \mathrm{mL}$ and added to the extracts distributed in 96-well plates. The extracts were used at concentrations of $2 \times$ MIC and $4 \times$ MIC. $1 \%$ DMSO (control vehicle), AMB (MIC; positive control) plus inoculum, and RPMI 1640 plus inoculum (negative control) were included in the tests as controls. Microplates were incubated at $37^{\circ} \mathrm{C}$. At different time points $(0,3,6,9,24,36$, and $48 \mathrm{~h}), 20 \mu \mathrm{L}$ aliquots were taken from each well and transferred to 96-well plates containing $180 \mu \mathrm{L}$ of PBS to perform ten-fold serial dilutions for each sample. Then, a $10 \mu \mathrm{L}$ aliquot from each dilution was plated on SDA and incubated at $37^{\circ} \mathrm{C}$ for $48 \mathrm{~h}$ to determine the colony-forming units $(\mathrm{CFU} / \mathrm{mL})$. The tests were performed in biological quadruplets. 


\subsection{Antivirulence Activity}

\subsubsection{Effect of PiHE and Fractions on Candida spp. Adhesion}

The assays were performed according to the previously published protocol, with some modifications [36]. Strains were grown in Yeast Nitrogen Base (YNB) plus glucose (50 mM) for $18 \mathrm{~h}$ at $37^{\circ} \mathrm{C}$. Samples were then centrifuged at $2060 \times \mathrm{g}$ for $5 \mathrm{~min}$, washed $2 \times$ with PBS, and suspended in PBS $(5 \mathrm{~mL})$, and their optical density was adjusted to $1 \times 10^{7} \mathrm{CFU} / \mathrm{mL}$. Inoculum (100 $\left.\mu \mathrm{L}\right)$ plus extracts $\left(100 \mu \mathrm{L} . \frac{1}{2} \mathrm{MIC}\right)$ were transferred to 96-well microplates and incubated for $90 \mathrm{~min}$ at $37^{\circ} \mathrm{C}$. Inoculum without extracts was used as a negative control. The supernatants were then discarded and the wells were washed twice with PBS. Subsequently, the adherent cells were resuspended in $100 \mu \mathrm{L}$ of PBS. Samples were serially diluted to determine the CFU/mL after growth in SDA $\left(48 \mathrm{~h}, 37^{\circ} \mathrm{C}\right)$. The tests were performed in biological quadruplicate.

\subsubsection{Effect of Extract and Fractions on Biofilm}

The assays were performed according to the previously published protocol [19], with certain modifications. The inoculum was cultured in Yeast Nitrogen Base Medium (YNB; Sigma-Aldrich) supplemented with $50 \mathrm{mM}$ of glucose and was incubated at $37^{\circ} \mathrm{C}$ for $18 \mathrm{~h}$. The microbial suspension was then centrifuged at $1666 \times g$ (Centrifuge 5810R, Eppendorf) for five minutes, and the cell pellet was washed twice with PBS and then resuspended in $5 \mathrm{~mL}$ PBS. Inoculum optical densities were adjusted to $1 \times 10^{7} \mathrm{CFU} / \mathrm{mL}$. Furthermore, $200 \mu \mathrm{L}$ from each of the yeast suspensions was transferred to 96-well polystyrene plates (Kasvi, Ortygia) and incubated for $90 \mathrm{~min}$ at $37^{\circ} \mathrm{C}$ to achieve adhesion. Then supernatants were aspirated, and the wells were washed twice with sterile PBS to remove any non-adhered cells.

To evaluate the inhibitory effects of the extracts on the formation of biofilms, $200 \mu \mathrm{L}$ of each extract and fractions at sub-inhibitory concentrations of $\frac{1}{4} \times \mathrm{MIC}$ and $\frac{1}{2} \times \mathrm{MIC}$ were diluted in YNB supplemented with $50 \mathrm{mM}$ glucose and were added to each well with adherent cells, followed by incubation for $24 \mathrm{~h} 37^{\circ} \mathrm{C}$. After incubation, the supernatant was aspirated, biofilms formed were washed twice with PBS and then evaluated by counting the CFU/mL, and metabolic activity was determined by an MTT (3-methyl-[4-5-dimethylthiazol-2-yl]-2,5-diphenyltetrazolium) (Sigma-Aldrich, St. Louis, MO, USA) assay and by staining with crystal violet.

To analyze the effect of the extract and fractions on pre-formed biofilms, microplates with adherent cells were incubated for $48 \mathrm{~h}$ at $37^{\circ} \mathrm{C}$. Culturing media was exchanged after $24 \mathrm{~h}$. Supernatants were aspirated, biofilms were washed twice with PBS, and extracts $(200 \mu \mathrm{L}$; at $2 \times \mathrm{MIC}$ and $4 \times \mathrm{MIC})$ diluted in YNB supplemented with $50 \mathrm{mM}$ glucose were added to each of the wells. Biofilms were incubated for another $24 \mathrm{~h}$ at $37^{\circ} \mathrm{C}$. After incubation, the supernatants were aspirated, biofilms were washed twice with PBS and then analyzed for CFU/mL, and metabolic activity was determined by MTT and by staining with crystal violet. In all experiments, biofilms without extracts and biofilms with AMB were used as a growth control and positive control, respectively.

\section{Colony Count Analysis of Biofilms}

After washing the biofilms twice with PBS, adhered biofilms were collected by scraping the bottom of each well plate and were suspended in $100 \mu \mathrm{L}$ of PBS. CFU/mL was determined by serially diluting each sample of biofilm, followed by plating $20 \mu \mathrm{L}$ of the suspension (quadruplets) on SDA and then counting the colonies after incubation at $37^{\circ} \mathrm{C}$ for $48 \mathrm{~h}$ [37].

\section{Biofilm Viability Assay}

The measurement of the metabolic activity of the cells in the biofilm was determined by the MTT method, according to [38], with some modifications. After washing biofilms $3 \times$ with PBS, $100 \mu L$ of MTT ( $5 \mathrm{mg} / \mathrm{mL}$; Sigma, USA) was added to each sample, which was then incubated for $4 \mathrm{~h}$ in the dark. The supernatants were then removed. Next, $100 \mu \mathrm{L}$ of DMSO was added to each well and the 
samples were incubated further for ten minutes. The plate absorbance was read in a microplate reader (Softmax ${ }^{\circledR}$ Pro) at $570 \mathrm{~nm}$. The experiments were performed six times on three different occasions.

Biofilm Analysis by Crystal Violet Staining

Biofilms were quantified using the crystal violet staining method [37]. Briefly, after washing the biofilms with PBS, they were dried at room temperature and fixed by resuspending them in $200 \mu \mathrm{L}$ of 95\% (v/v) methanol, followed by 15 min of incubation. Furthermore, the methanol was removed, and the plates were dried for $20 \mathrm{~min}$ at room temperature. Next, $200 \mu \mathrm{L}$ of crystal violet $(1 \% \mathrm{v} / \mathrm{v})$ was added to each well and the samples were incubated for five minutes with the stain. Plates were washed twice with PBS and $200 \mu \mathrm{L}$ of acetic acid (33\% v/v) was added to each well. To obtain absorbance values, $100 \mu \mathrm{L}$ from each of the sample wells was transferred to a new 96-well microplate and read at $570 \mathrm{~nm}$ in the microplate reader. The experiments were repeated six times on three different occasions.

\subsection{Flow Cytometry Analysis for Examining the Effect of the Extract and Fractions on the Mitochondrial Membrane Potential $(\Delta \Psi m)$ and Lysosomal Membrane Stability}

The stability of the lysosomal membrane and the mitochondrial membrane potential $(\Delta \Psi \mathrm{m})$ were assessed by flow cytometry using the Acridine Orange (AO) and Rhodamine 123 (Rho 123) fluorescence probes, respectively $[39,40]$. The assays were carried out with C. albicans SC 5314 and C. glabrata ATCC 2001 strains, according to the procedure of Alves et al. [31], with some modifications.

The strains were resuspended in $500 \mu \mathrm{L}$ of MOPS-buffered RPMI-1640 at a density of $1.0 \times 10^{6}$ cells $/ \mathrm{mL}$. The extract and fractions were added to the cell suspensions at concentrations of $1 \times \mathrm{MIC}$ and $2 \times \mathrm{MIC}$ and incubated for $24 \mathrm{~h}$ at $37^{\circ} \mathrm{C}$. After incubation, the cells were centrifuged at $3800 \times g$, for $10 \mathrm{~min}$ (Centrifuge 5810R, Eppendorf), washed thrice with PBS (pH 7.2), resuspended in $500 \mu \mathrm{L}$ of PBS, and labeled with AO $(1 \mu \mathrm{g} / \mathrm{mL}$ in the dark, $20 \mathrm{~min})$ or Rho $123(10 \mu \mathrm{g} / \mathrm{mL}$ in the dark, $10 \mathrm{~min})$. After incubation with the labels, the cells were washed thrice with PBS, resuspended in PBS, and analyzed by flow cytometry (BD Accuri ${ }^{\text {TM }}$, United States, FL3 channel for AO and FL1 for Rho123). The variation index (VI), calculated by the formula (MT-MC)/MC (MC = mean fluorescence intensity of control cells; MT = mean fluorescence intensity of treatments), showed the changes in the fluorescence intensity of Rho 123. When the mitochondrial membrane is depolarized, the VI values are negative.

\subsection{Cytotoxicity Analysis Using Murine RAW 264.7 Cells}

Murine RAW 264.7 cells were procured from the Cell Bank of Rio de Janeiro-Paul Ehrlich Scientific-Technical Association (APABCAM-Rio de Janeiro, RJ, Brazil) and maintained at the Immunophysiology Laboratory (LIF) of the Federal University of Maranhão. Cells were cultivated in Dulbecco's high glucose modified Eagle's medium (DMEM) supplemented with 10\% fetal bovine serum (Sigma-Aldrich) and penicillin-streptomycin (1\%) antibiotic solution. Cells were incubated at $37^{\circ} \mathrm{C}$ under $5 \% \mathrm{CO}_{2}$ and humidity. The culture media was renewed every $48 \mathrm{~h}$ and the cells were cultured until they reached $70 \%$ confluency. Cells were scrapped with a cell scarper for further experiments.

For the assay, $1 \times 10^{5}$ cells/mL $(100 \mu \mathrm{L})$ were plated in 96 -well plates and incubated at $37^{\circ} \mathrm{C}$, under $5 \% \mathrm{CO}_{2}$ for $4 \mathrm{~h}$, to achieve cell adhesion. Next, the supernatant was removed, and the cells were treated with PiHE, DCMF, and EAF $(0.05-50 \mathrm{mg} / \mathrm{mL})$ and incubated for $24 \mathrm{~h}$ at $37^{\circ} \mathrm{C}$, under $5 \% \mathrm{CO}_{2}$. $1 \%$ DMSO (vehicle), untreated cells, and cell-free media were used as control groups. After incubation, the supernatant was removed, and the adhered cells were evaluated by the MTT assay as follows. RPMI medium containing $5 \mathrm{mg} / \mathrm{mL}$ was placed in each well, MTT was added, and plates were incubated for $4 \mathrm{~h}$ at $37^{\circ} \mathrm{C}$ under $5 \% \mathrm{CO}_{2}$ in the dark. Supernatants were discarded, and the formed crystals were dissolved in $100 \mu \mathrm{L}$ SDS (10\% dodecyl sodium sulfate) overnight. The optical density (OD) was read at $570 \mathrm{~nm}$ using a microplate reader (Softmax ${ }^{\circledR}$ Pro), and the cellular viability was expressed as a percentage of viable cells in relation to the positive control and reported as the mean of three independent assays [41]. 


\subsection{Hemolytic Activity}

Defibrinated sheep's blood (EB FARMA, Rio de Janeiro, RJ, BR) was used for this assay. The erythrocytes were isolated by centrifugation at 290 $\mathrm{g}$ (Centrifuge 5810R, Eppendorf) for $10 \mathrm{~min}$ at $4{ }^{\circ} \mathrm{C}$. After removal of the plasma, erythrocytes were washed three times with PBS (pH 7.4) and soon after, were resuspended in the same buffer at $2 \%(\mathrm{v} / \mathrm{v})$. To evaluate the hemolytic activity of extracts and fractions, $100 \mu \mathrm{L}$ aliquots of the erythrocyte solution were added to flat bottom 96-well microplates at different concentrations of the extract and fractions $(0.05$ to $50 \mathrm{mg} / \mathrm{mL})$. Total hemolysis was achieved with 1\% Triton x-100 (Sigma-Aldrich), while PBS was used as a negative control. 1\% DMSO (vehicle) was also used as a control. After incubation for $60 \mathrm{~min}$ at room temperature, the cells were centrifuged at $300 \times g$ for $10 \mathrm{~min}$ and the supernatant was used to measure the absorbance at $540 \mathrm{~nm}$ [42]. The relative hemolytic activity was expressed in relation to Triton X-100, calculated by the following formula:

$$
\text { Relative hemolytic activity }(\%)=[(A s-A b) \times 100] /(A c-A b),
$$

where $(A b)$ is the control absorbance (blank, without extract), $(A s)$ stands for absorbance in the presence of the extract, and $(A c)$ stands for absorbance in the presence of Triton $\mathrm{X}-100$. Assays were performed as biological quadruplets.

\subsection{Statistical Analysis}

Statistical analysis was performed using GraphPad Prism 7.00 Inc. Software. Normality tests were performed, and data were analyzed by a univariate analysis of variance (ANOVA) followed by the Tukey test, with a significance level of $p<0.05$.

\section{Conclusions}

A pure hydroalcoholic extract and fractions from P. insignis leaves were active against Candida spp., but were not cytotoxic to RAW 264.7 cells. The extract and fractions also showed high anti-adhesion and anti-biofilm activities. EAF stood out as the best candidate as it was highly efficient in killing the fungal cells and significantly inhibited the virulence properties of Candida spp., such as cell adhesion and biofilm formation. The main antifungal chemical components in the extract were the glycosylated flavonoids derived from quercetin and myricetin, which interfered with or were bound to specific components of the fungal membrane. Our work contributes to the development of a new and efficient treatment of candidiasis and further studies are being developed in our laboratory using bioinformatics and animal models to further validate our data, as well as to test the topical use of these compounds.

Author Contributions: Conceptualization, A.F.d.S., R.N.M.G., and C.A.M.; methodology, A.F.d.S., C.Q.d.R., A.R.C.J., I.N.F.V.M., A.B.d.A., J.R.F., E.P.M., R.d.S.S., C.D.L.C., D.H.d.S.S., and A.d.S.O.; software, A.F.d.S., L.C.N.d.S., and C.Q.d.R.; validation, A.F.d.S., C.A.M., and R.N.M.G.; formal analysis, A.F.d.S., L.C.N.d.S., C.A.M., F.R.F.N., and C.Q.d.R.; investigation, A.F.d.S., D.H.d.S.S., C.D.L.C., A.d.S.O., and A.B.d.A.; resources, C.A.M. and R.N.M.G..; data curation, C.A.M.; writing-original draft preparation, A.F.d.S. and C.A.M.; writing-review and editing, C.A.M., L.C.N.d.S., and R.N.M.G.; supervision, C.A.M.; project administration, A.F.d.S. and C.A.M.; funding acquisition, R.N.M.G. All authors have read and agreed to the published version of the manuscript.

Funding: This research was funded by FAPEMA (Fundação de Amparo à Pesquisa e ao Desenvolvimento Científico e Tecnológico do Maranhão), CNPq (Conselho Nacional de Desenvolvimento em Pesquisa), and CAPES (Coordenação de Aperfeiçoamento de Pessoal de Nível Superior) Brazilian funding agencies.

Acknowledgments: The authors are grateful to FAPEMA (Fundação de Amparo ao Desenvolvimento Tecnológico do Maranhão) for Carmem Duarte Lima Campos' Master's scholarship and CNPq (Conselho Nacional de Desenvolvimento em Pesquisa) for the Rayssa de Sousa Silva Scientific Initiation scholarship.

Conflicts of Interest: The authors declare no conflicts of interest. The funding agencies had no role in the design of the study, in the collection, analyses, or interpretation of data; in the writing of the manuscript; or in the decision to publish the results. 


\section{References}

1. Muthamil, S.; Balasubramaniam, B.; Balamurugan, K.; Pandian, S.K. Synergistic Effect of Quinic Acid Derived From Syzygium cumini and Undecanoic Acid Against Candida spp. Biofilm and Virulence. Front. Microbiol. 2018, 9, 2835. [CrossRef] [PubMed]

2. Cassone, A. Vulvovaginal Candida albicans infections: Pathogenesis, immunity and vaccine prospects. BJOG Int. J. Obstet. Gynaecol. 2015, 122, 785-794. [CrossRef] [PubMed]

3. Sobel, J.D. Recurrent vulvovaginal candidiasis. Am. J. Obstet. Gynecol. 2016, 214, 15-21. [CrossRef] [PubMed]

4. Foxman, B.; Muraglia, R.; Dietz, J.P.; Sobel, J.D.; Wagner, J. Prevalence of Recurrent Vulvovaginal Candidiasis in 5 European Countries and the United States: Results From an Internet Panel Survey. J. Low. Genit. Tract Dis. 2013, 17, 340-345. [CrossRef]

5. Tang, H.J.; Liu, W.L.; Lin, H.L.; Lai, C.C. Epidemiology and prognostic factors of candidemia in cancer patients. PLoS ONE 2014, 9, e99103. [CrossRef]

6. Tsui, C.; Kong, E.F.; Jabra-Rizk, M.A. Pathogenesis of Candida albicans Biofilm. Pathog. Dis. 2016, 7. [CrossRef]

7. Enfert, C.; Janbon, G. Biofilm formation in Candida glabrata: What have we learnt from functional genomics approaches? FEMS Yeast Res. 2016, 16, 1-13. [CrossRef]

8. De Oliveira Santos, G.C.; Vasconcelos, C.C.; Lopes, A.J.O.; de Sousa Cartágenes, M.S.; Filho, A.K.D.B.; do Nascimento, F.R.F.; Ramos, R.M.; Pires, E.R.R.B.; de Andrade, M.S.; Rocha, F.M.G.; et al. Candida Infections and Therapeutic Strategies: Mechanisms of Action for Traditional and Alternative Agents. Front. Microbiol. 2018, 9, 1351. [CrossRef]

9. Yang, L.; Liu, X.; Zhuang, X.; Feng, X.; Zhong, L.; Ma, T. Antifungal Effects of Saponin Extract from Rhizomes of Dioscorea panthaica Prain et Burk against Candida albicans. Evid. Based Complement. Altern. Med. 2018. [CrossRef]

10. Rodrigues, K.; Ramos, D.F.; Carrion, L.L.; Cursino, L.M.C.; Jefreys, M.F.; Pedroza, L.S.; Osório, M.I.C.; Oliveira, J.L.; Andrade, J.I.A.; Fernandes, C.C.; et al. Antifungal activity of brazilian amazon plants extracts against some species of Candida spp. Int. J. Phytopharmacol. 2014, 5, 445-453.

11. Souza, A.C.; Alves, M.M.M.; Brito, L.M.; Oliveira, L.G.C.; Sobrinho-Júnior, E.P.C.; Costa, I.C.G.; Freitas, S.D.L.; Rodrigues, K.A.F.; Chaves, M.H.; Arcanjo, D.D.R.; et al. Platonia insignis Mart., a Brazilian Amazonian Plant: The Stem Barks Extract and Its Main Constituent Lupeol Exert Antileishmanial Effects Involving Macrophages Activation. Evid. Based Complement. Altern. Med. 2017, 2017. [CrossRef] [PubMed]

12. Costa Júnior, J.S.; Almeida, A.A.C.; Ferraz, A.B.F.; Rossatto, R.R.; Silva, T.G.; Silva, P.B.N.; Militão, G.C.G.; Citó, A.M.G.L.; Santana, L.C.L.R.; Carvalho, F.A.A.; et al. Cytotoxic and leishmanicidal properties of garcinielliptone FC, a prenylated benzophenone from Platonia insignis. Nat. Prod. Res. 2013, 27, 470-474. [CrossRef] [PubMed]

13. Yamaguchi, K.K.L.; Pereira, C.V.L.; Lima, E.S.; Veiga Junior, V.F. Química e farmacologia do bacuri (Platonia insignis). Sci. Amazon. 2014, 3, 39-46.

14. Costa Júnior, J.S.; Ferraz, A.B.F.; Sousa, T.O.; Silva, R.A.C.; Lima, S.G.; Feitosa, C.M.; Citó, A.M.G.L.; Cavalcante, A.A.C.M.; Freitas, R.M.; Speroto, A.R.M.; et al. Investigation of Biological Activities of Dichloromethane and Ethyl Acetate Fractions of Platonia insignis Mart. Seed. Basic Clin. Pharmacol. Toxicol. 2013, 112, 34-41. [CrossRef]

15. Carvalho, J.E.U.; Nascimento, W.M.O. Bacuri. Platonia Insignis; Instituto Interamericano de Cooperación para la Agricultura (IICA): San José, Costa Rica, 2017.

16. Nascimento, J.L.; Coêlho, A.G.; Barros, Y.S.O.; Silva, O.A.; Freitas, R.M.; Rocha, M.S.; David, J.M.; Costa Júnior, J.S.; Arcanjo, D.D.R.; Oliveira, R.C.M.; et al. Avaliação da atividade antioxidante in vitro do extrato hexânico da semente do bacuri (Platonia insignis Mart.) e de seu complexo de inclusão com $\beta$-ciclodextrina. Bol. Inf. Geum 2014, 5, 44-53.

17. Siddiqui, Z.N.; Farooq, F.; Musthafa, T.N.M.; Ahmad, A.; Khan, A.U. Synthesis, characterization and antimicrobial evaluation of novel halopyrazole derivatives. J. Saudi Chem. Soc. 2013, 17, 237-243. [CrossRef]

18. Cavalheiro, M.; Teixeira, M.C. Candida Biofilms: Threats, Challenges, and Promising Strategies. Front. Med. 2018, 5, 28. [CrossRef]

19. Seneviratne, C.J.; Rajan, S.; Wong, S.S.W.; Tsang, D.N.C.; Lai, C.K.C.; Samaranayake, L.P.; Jin, L. Antifungal Susceptibility in Serum and Virulence Determinants of Candida Bloods tream Isolates from Hong Kong. Front. Microbiol. 2016, 7, 216. [CrossRef] 
20. Lohse, M.B.; Gulati, M.; Johnson, A.D.; Nobile, C.J. Development and regulation of single- and multi-species Candida albicans biofilms. Nat. Rev. Microbiol. 2018, 16, 19-31. [CrossRef]

21. Seneviratne, C.J.; Jin, L.J.; Samaranayake, Y.H.; Samaranayake, L.P. Cell density and cell aging as factors modulating antifungal resistance of Candida albicans biofilms. Antimicrob. Agents Chemother. 2008, 52, 3259-3266. [CrossRef]

22. Teodoro, G.R.; Gontijo, A.V.L.; Salvador, M.J.; Tanaka, M.H.; Brighenti, F.L.; Delbem, A.C.B.; Delbem, Á.C.B.; Koga-Ito, C.Y. Effects of Acetone Fraction From Buchenavia tomentosa Aqueous Extract and Gallic Acid on Candida albicans Biofilms and Virulence Factors. Front. Microbiol. 2018, 9, 647. [CrossRef] [PubMed]

23. Girardot, M.; Imbert, C. Novel strategies against Candida biofilms: Interest of synthetic compounds. Future Microbiol. 2016, 11, 69-79. [CrossRef] [PubMed]

24. Watamoto, T.; Egusa, H.; Sawase, T.; Yatani, H. Screening of Pharmacologically Active Small Molecule Compounds Identifies Antifungal Agents Against Candida Biofilms. Front. Microbiol. 2015, 6, 1453. [CrossRef] [PubMed]

25. Alalwan, H.; Rajendran, R.; Lappin, D.F.; Combet, E.; Shahzad, M.; Robertson, D.; Nile, C.J.; Williams, C.; Ramage, G. The Anti-Adhesive Effect of Curcumin on Candida albicans Biofilms on Denture Materials. Front. Microbiol. 2017, 8, 659. [CrossRef]

26. Ludovico, P.; Sansonetty, F.; Côrte-Real, M. Assessment of mitochondrial membrane potential in yeast cell populations by flow cytometry. Microbiology 2001, 147, 3335-3343. [CrossRef]

27. Silva, C.R.; Andrade Neto, J.B.; Sousa Campos, R.; Figueiredo, N.S.; Sampaio, L.S.; Magalhaes, H.I.F.; Cavalcante, B.C.; Gaspar, D.M.; Andrade, G.M.; Lima, I.S.P.; et al. Synergistic Effect of the Flavonoid Catechin, Quercetin, or Epigallocatechin Gallate with Fluconazole Induces Apoptosis in Candida tropicalis Resistant to Fluconazole. Antimicrob. Agents Chemother. 2014, 58, 1468-1478. [CrossRef]

28. Neto, J.B.A.; da Silva, C.R.; Neta, M.A.S.; Campos, R.S.; Siebra, J.T.; Silva, R.A.C.; Gaspar, D.M.; Magalhães, H.I.F.; de Moraes, M.O.; Lobo, M.D.P.; et al. Antifungal Activity of Naphthoquinoidal Compounds In Vitro against Fluconazole Resistant Strains of Different Candida Species: A Special Emphasis on Mechanisms of Action on Candida tropicalis. PLoS ONE 2014, 9, e93698. [CrossRef]

29. Lee, M.H.; Han, D.W.; Hyon, S.H.; Park, J.C. Apoptosis of human fibrosarcoma HT-1080 cells by epigallocatechin-3-O-gallate via induction of p53 and caspases as well as suppression of Bcl-2 and phosphorylated nuclear factor- B. Apoptosis 2011, 16, 75-85. [CrossRef]

30. Hwang, B.; Hwang, J.S.; Lee, J.; Kim, J.K.; Kim, S.R.; Kim, Y.; Lee, D.G. Induction of yeast apoptosis by an antimicrobial peptide, papiliocin. Biochem. Biophys. Res. Commun. 2011, 408, 89-93. [CrossRef]

31. Neto, W.R.N.; Farah, E.I.; Santos, Á.R.C.; Mendes, B.S.; Sousa, L.V.N.F.; Rodrigues, J.F.S.; Alves, J.C.O.; Ferreira, G.F.; Santos, J.R.; Santos, L.C.N.; et al. Eugenol Induces Phenotypic Alterations and Increases the Oxidative Burst in Cryptococcus. Front. Microbiol. 2017, 8, 2419. [CrossRef]

32. Clinical and Laboratory Standards Institute. Reference Method for Broth Dilution Antifungal Susceptibility Testing of Yeasts; Fourth informational supplement; M27-S4; Clinical and Laboratory Standards Institute: Wayne, PA, USA, 2012.

33. Terças, A.G.; Monteiro, A.S.; Moffa, E.B.; Santos, J.R.A.; Sousa, E.M.; Pinto, A.R.B.; Costa, P.C.S.; Borges, A.C.R.; Torres, L.M.B.; Barros Filho, A.K.D.; et al. Phytochemical Characterization of Terminalia catappa Linn. Extracts and Their antifungal Activities against Candida spp. Front. Microbiol. 2017, 8, 595. [CrossRef] [PubMed]

34. Freires, I.A.; Murata, R.M.; Furletti, V.F.; Sartoratto, A.; Alencar, S.M.; Figueira, G.M.; de Oliveira Rodrigues, J.A.; Duarte, M.C.T.; Rosalen, P.L. Coriandrum sativum L. (Coriander) Essential Oil: Antifungal Activity and Mode of Action on Candida spp., and Molecular Targets Affected in Human Whole-Genome Expression. PLoS ONE 2014, 9, e99086. [CrossRef] [PubMed]

35. Seleem, D.; Benso, B.; Noguti, J.; Pardi, V.; Murata, R.M. In Vitro and In Vivo Antifungal Activity of Lichochalcone-against Candida albicans Biofilms. PLoS ONE 2016, 11, e0157188. [CrossRef] [PubMed]

36. Gulati, M.; Lohse, M.B.; Ennis, C.L.; Gonzalez, R.E.; Perry, A.M.; Bapat, P.; Valle Arevalo, A.; Rodriguez, D.L.; Nobile, C.J. In vitro culturing and screening of Candida albicans biofilms. Curr. Protoc. Microbiol. 2018, e60. [CrossRef]

37. Zago, C.E.; Silva, S.; Sanitá, P.V.; Barbugli, P.A.; Dias, C.M.I.; Lordello, V.B.; Vergani, C.E. Dynamics of Biofilm Formation and the Interaction between Candida albicans and Methicillin-Susceptible (MSSA) and -Resistant Staphylococcus aureus (MRSA). PLoS ONE 2015, 10, e0123206. [CrossRef] 
38. Da Silva, A.R.; de Andrade Neto, J.B.; da Silva, C.R.; Campos, R.D.S.; Costa Silva, R.A.; Freitas, D.D.; Nascimento, F.B.S.A.; de Andrade, L.N.D.; Sampaio, L.S.; Grangeiro, T.B.; et al. Berberine antifungal activity in fluconazole-resistant pathogenic yeasts: Action mechanism evaluated by flow cytometry and biofilm growth inhibition in Candida spp. Antimicrob. Agents Chemother. 2016, 60, 3551-3557. [CrossRef]

39. Ronot, X.; Benel, L.; Adolphe, M.; Mounolou, J.C. Mitochondrial analysis in living cells: The use of rhodamine 123 and flowcytometry. Biol. Cell 1986, 57, 1-7. [CrossRef]

40. Olsson, M.; Rundquist, I.; Brunk, U. Flow cytofluorometry of lysosomal acridine orange uptake by living cultured cells. Effect of trypsinization and starvation. Acta Pathol. Microbiol. Immunol. Scand. 1987, 95, 159-165. [CrossRef]

41. Chen, L.; Zhang, Y.; Liu, J.; Wei, L.; Song, B.; Shao, L. Exposure of the murine RAW 264.7 macrophage cell line to dicalcium silicate coating: Assessment of cytotoxicity and pro-inflammatory effects. J. Mater. Sci. Mater. Med. 2016, 27, 59. [CrossRef]

42. Silva, A.P.S.; Nascimento, S.L.C.; Martins, F.C.S.; Araújo, J.M.; Correia, M.T.S.; Cavalcanti, M.S.; Lima, V.L.M. Antimicrobial Activity and Phytochemical Analysis of Organic Extracts from Cleome spinosa Jaqc. Front. Microbiol. 2016, 7, 963. [CrossRef]

(C) 2020 by the authors. Licensee MDPI, Basel, Switzerland. This article is an open access article distributed under the terms and conditions of the Creative Commons Attribution (CC BY) license (http://creativecommons.org/licenses/by/4.0/). 